OPEN ACCESS

Edited by:

Sophie Bleves,

Aix-Marseille University, France

Reviewed by:

Erin J. Van Schaik,

Texas A\&M Health Science Center,

United States

Erin C. Garcia,

University of Kentucky College of Medicine, United States

Brian H. Kvitko,

University of Georgia, United States

*Correspondence:

Joanne M. Stevens

jo.stevens@roslin.ed.ac.uk

Received: 20 March 2017 Accepted: 31 May 2017

Published: 15 June 2017

Citation:

Vander Broek CW and Stevens JM

(2017) Type III Secretion in the Melioidosis Pathogen Burkholderia

pseudomallei.

Front. Cell. Infect. Microbiol. 7:255

doi: $10.3389 / f c i m b .2017 .00255$

\section{Type III Secretion in the Melioidosis Pathogen Burkholderia pseudomallei}

\author{
Charles W. Vander Broek and Joanne M. Stevens * \\ The Roslin Institute and Royal (Dick) School of Veterinary Studies, University of Edinburgh, Midlothian, United Kingdom
}

Burkholderia pseudomallei is a Gram-negative intracellular pathogen and the causative agent of melioidosis, a severe disease of both humans and animals. Melioidosis is an emerging disease which is predicted to be vastly under-reported. Type III Secretion Systems (T3SSs) are critical virulence factors in Gram negative pathogens of plants and animals. The genome of $B$. pseudomallei encodes three T3SSs. T3SS-1 and -2, of which little is known, are homologous to Hrp2 secretion systems of the plant pathogens Ralstonia and Xanthomonas. T3SS-3 is better characterized and is homologous to the Inv/Mxi-Spa secretion systems of Salmonella spp. and Shigella flexneri, respectively. Upon entry into the host cell, B. pseudomallei requires T3SS-3 for efficient escape from the endosome. T3SS-3 is also required for full virulence in both hamster and murine models of infection. The regulatory cascade which controls T3SS-3 expression and the secretome of T3SS-3 have been described, as well as the effect of mutations of some of the structural proteins. Yet only a few effector proteins have been functionally characterized to date and very little work has been carried out to understand the hierarchy of assembly, secretion and temporal regulation of T3SS-3. This review aims to frame current knowledge of $B$. pseudomallei T3SSs in the context of other well characterized model T3SSs, particularly those of Salmonella and Shigella.

Keywords: T3SS, effector, translocator, Burkholderia pseudomallei, melioidosis

\section{INTRODUCTION}

Bacteria are required to adapt to and survive in constantly changing and harsh environments. In order to respond to and alter their environment, secretion systems have evolved in bacteria to export proteins into the surrounding milieu (reviewed in Costa et al., 2015). One secretion system in Gram-negative bacteria that has been the focus of much research in the last three decades is the Type III secretion system (T3SS) (reviewed in Galán et al., 2014). Type III Secretion Systems (T3SSs) have been shown to be important for virulence in many Gram-negative bacterial pathogens of animals and plants; including Pseudomonas syringae, Xanthomonas, Ralstonia solanacearum, Erwinia, pathogenic Escherichia coli, Salmonella, Shigella, Yersinia, and Burkholderia (Gemski et al., 1980; Maurelli et al., 1985; Galán and Curtiss, 1989; Jarvis et al., 1995; Stevens et al., 2002; Büttner and He, 2009). T3SSs span the bacterial inner and outer membranes forming a "molecular syringe" which allows bacteria to export proteins, called effectors, from the bacterial cytoplasm into a target eukaryotic cell (reviewed in Galán et al., 2014).

The focus of this review is T3SSs in the pathogenic bacterium Burkholderia pseudomallei, and to some extent the closely related species $B$. mallei and B. thailandensis. Originally described in drug addicts in Rangoon in the early twentieth century by Alfred Whitmore (Whitmore, 1913), Burkholderia pseudomallei is a facultative intracellular pathogen (Pruksachartvuthi et al., 1990) 
that is the causative agent of melioidosis, or Whitmore's disease. Melioidosis is a severe disease of humans and animals, causing an estimated 165,000 cases of human melioidosis per year resulting in a predicted 89,000 deaths (Limmathurotsakul et al., 2016). Infection with $B$. pseudomallei is usually associated with environmental exposure and can occur through breaks in the skin, inhalation or ingestion (reviewed in Cheng and Currie, 2005). In the majority of cases, the incubation period for melioidosis is between 1 and 21 days following infection (Ngauy et al., 2005). About 50\% of melioidosis cases affect people with diabetes and other important risk factors include lung disease, cystic fibrosis and excessive alcohol consumption (Currie et al., 2010). There are varied clinical presentations of B. pseudomallei infection ranging from skin infections to pneumonia and septic shock, which hampers accurate diagnosis in a clinical setting (Currie et al., 2010). B. pseudomallei is reported to be able to reactivate after remaining latent following a primary infection. The longest reported period between infection and reactivation occurred in a World War II veteran who manifested symptoms 62 years after exposure (Ngauy et al., 2005). B. pseudomallei has been classified as a bioterrorism agent by both the UK government and the US Centres for Disease Control and Prevention (reviewed in Rotz et al., 2002; Cheng and Currie, 2005).

B. mallei, the causative agent of glanders in horses and other solipeds, is a zoonotic pathogen with restricted host range (Yabuuchi et al., 1992; Srinivasan et al., 2001). In humans, B. mallei causes a disease similar to melioidosis and has been similarly classified as a potential bioterrorism agent in the UK and US (Rotz et al., 2002; Van Zandt et al., 2013). The soil saprophyte $B$. thailandensis is non-pathogenic and present in high numbers in the soils and standing waters of endemic areas. This species is commonly used as an alternative model system for B. pseudomallei and B. mallei studies as its genome encodes many homologs of virulence factors from these pathogenic species (Brett et al., 1998; Moore et al., 2004; Yu et al., 2006; Haraga et al., 2008).

\section{TYPE THREE SECRETION SYSTEMS IN B. PSEUDOMALLEI}

The B. pseudomallei genome encodes three T3SSs which are referred to as T3SS-1, T3SS-2, and T3SS-3. The genome of B. pseudomallei consists of two circular chromosomes, with all three T3SSs residing on chromosome 2 (Holden et al., 2004). T3SS-2 and T3SS-3 are present in the genomes of $B$. mallei and $B$. thailandensis, whereas T3SS-1 is absent from both (Rainbow et al., 2002). T3SS-1 and T3SS-2 are relatively poorly characterized and share homology with the Hrp2 family of T3SSs found in plant pathogens (Winstanley et al., 1999; Rainbow et al., 2002). The best characterized of the B. pseudomallei T3SSs, T3SS3 , is also known as the Burkholderia secretion apparatus (Bsa) T3SS. It is a member of the Inv-Mxi-Spa family of T3SSs from Salmonella spp. (SPI-1) and Shigella flexneri (Attree and Attree, 2001; Stevens et al., 2002; Egan et al., 2014).

Burkholderia pseudomallei T3SS-1 (BPSS1390-BPSS1410) and T3SS-2 (BPSS1610-BPSS1629) show closest homology to the
Hrp2 T3SS of the plant pathogen Ralstonia solanacearum (Angus et al., 2014). B. pseudomallei T3SS-2 expression is activated by the AraC-type regulator HrpB (BPSS1610) (Lipscomb and Schell, 2011). HrpB also regulates the expression of a type IV pilus encoded directly upstream of T3SS-2, but does not appear to regulate the other T3SSs in B. pseudomallei (Lipscomb and Schell, 2011). In order to investigate the role that T3SS-1 and T3SS-2 play in plants, a tomato plant infection model was established for B. pseudomallei and B. thailandensis (Lee et al., 2010). B. pseudomallei KHW T3SS-1 and T3SS-2 mutants were reported to be attenuated in tomato plants (Lee et al., 2010). However, in a more recent study, B. thailandensis did not display phytopathogenic activity in tomato plants which were treated identically to those in Lee et al. (2010), Lipscomb and Schell (2011). The question of whether B. pseudomallei is capable of infecting plants, and what if any role T3SS-1 and -2 have in this process, remain important unanswered questions.

The function of T3SS- 1 and -2 in mammalian systems has also been investigated to some extent. T3SSs- 1 and -2 do not appear to be required for vacuole escape of the bacterium into the cytoplasm of infected macrophages (Burtnick et al., 2008), and are dispensable in a Syrian hamster model of infection (Warawa and Woods, 2005). However, a B. pseudomallei T3SS-1 mutant displayed increased co-localisation with the autophagy marker LC3 and a reduction in intracellular survival in RAW264.7 cells (D'Cruze et al., 2011). In the same study, T3SS-1 was required for full virulence in a respiratory murine model of melioidosis (D'Cruze et al., 2011). Both earlier studies inactivated T3SS1 by mutating the structural auto-protease component (BpscU, Table 1) (Warawa and Woods, 2005; Burtnick et al., 2008) while the latter study generated a system knockout by mutation of the ATPase (BpscN, Table 1), which may account for the different phenotypes observed.

\section{T3SS-3}

The best characterized of the three T3SSs, T3SS-3 (BPSS1516BPSS1552, Figure 1) is a member of the Inv/Mxi-Spa family of T3SSs (Egan et al., 2014) of which the prototypic systems are found in Salmonella Spp. and Shigella flexneri. The Salmonella and Shigella prototypic systems are required in these bacteria for host cell invasion and escape from the endocytic vacuole into the cytosol, respectively (reviewed in Galán et al., 2014). B. pseudomallei is a facultative intracellular pathogen capable of survival in both phagocytic and non-phagocytic cell lines (Jones et al., 1996). T3SS-3 is required for B. pseudomallei to efficiently escape the endocytic vesicle (Stevens et al., 2002). The T3SS-3 is also required for full virulence in both murine and Syrian hamster models of infection (Stevens et al., 2004; Warawa and Woods, 2005; Gutierrez et al., 2015a). T3SS-3 deficient mutants are also impaired in their ability to disseminate from the lungs of mice infected intra-nasally (Gutierrez et al., 2015a). A recent study used Tn-seq to identify genes required for respiratory melioidosis in mice and identified the following T3SS-3 genes as being required: bprA (BPSS1530), bipC (BPSS1531), bipB (BPSS1532), bicA (BPSS1533), bsaZ (BPSS1534), bsaW (BPSS1537), bsaV (BPSS1538), bsaO (BPSS1545), bsaM (BPSS1547), bsaL (BPSS1548), bsaK (BPSS1549), and bsaJ 
TABLE $1 \mid$ B. pseudomallei T3SS-1 and -2 genes, corresponding proteins and predicted functions.

\begin{tabular}{|c|c|c|c|c|c|c|}
\hline \multicolumn{2}{|c|}{ B. pseudomallei K96243 } & \multicolumn{2}{|c|}{$\begin{array}{c}\text { B. pseudomallei K96243 } \\
\text { T3SS-2 }\end{array}$} & \multirow{2}{*}{$\begin{array}{l}\text { R. solanacearum } \\
\text { Hrp2 } \\
\text { Protein name }\end{array}$} & \multirow{2}{*}{$\frac{\text { Universal Nomenclature }}{\text { Protein name }}$} & \multirow[t]{2}{*}{ Predicted function } \\
\hline Locus tag & Protein name & Locus tag & Protein name & & & \\
\hline BPSS1388 & $\begin{array}{l}\text { Similar to Hrpk1 } \\
\text { from P. syringae }\end{array}$ & & & & & Translocator \\
\hline BPSS1390 & BpscC & BPSS1592 & BpscC2 & $\mathrm{HrcC}$ & SctC & Outer membrane ring / secretin \\
\hline BPSS1392 & BpscT & BPSS1629 & BpscT2 & HrcT & SctT & Inner membrane export apparatus \\
\hline BPSS1393 & BpspD & BPSS1628 & BpspD2 & HrpD & SctO & Stalk protein \\
\hline BPSS1394 & $\mathrm{BpscN}$ & BPSS1627 & BpscN2 & $\mathrm{HrcN}$ & SctN & ATPase \\
\hline BPSS1395 & BpscL & BPSS1626 & BpscL2 & $\mathrm{HrcL}$ & SctL & Stator protein \\
\hline BPSS1396 & $\mathrm{BpspH}$ & BPSS1625 & $\mathrm{BpspH} 2$ & $\mathrm{HrpH}$ & & Inner membrane component \\
\hline BPSS1401 & $\mathrm{BpscV}$ & BPSS1620 & BpscV2 & $\mathrm{HrcV}$ & SctV & Export gate \\
\hline BPSS1402 & BpsaP & BPSS1619 & BpsaP2 & HpaP & SctP & Regulates needle length / translocator secretion \\
\hline BPSS1403 & $\mathrm{BpscQ}$ & BPSS1618 & BpscQ2 & $\mathrm{HrcQ}$ & SctQ & Cytoplasmic ring \\
\hline BPSS1404 & BpscR & BPSS1617 & BpscR2 & $\mathrm{HrcR}$ & SctR & Inner membrane export apparatus \\
\hline BPSS1405 & BpscS & BPSS1616 & BpscS2 & HrcS & SctS & Inner membrane export apparatus \\
\hline BPSS1406 & BpspV & BPSS1615 & BpspV2 & HrpV & & Secreted regulator \\
\hline BPSS1407 & BpscD & BPSS1614 & BpscD2 & $\mathrm{HrcD}$ & SctD & Inner membrane ring component \\
\hline BPSS1410 & BpsaB & BPSS1611 & BpsaB2 & НpaB & & Chaperone \\
\hline
\end{tabular}

Homologs from R. solanacearum Hrp2 T3SS are given for reference. Where applicable, the universal nomenclature for T3SS structural proteins is also listed to allow for comparison to genes from T3SS-3 listed in Table 2.

(BPSS1550) (Gutierrez et al., 2015b). This highlights the importance of T3SS-3 in melioidosis.

\section{TRANSCRIPTIONAL REGULATION OF T3SS-3}

The transcriptional regulation of T3SS-3 has been elucidated (Sun et al., 2010). At the top of the regulatory hierarchy is the gene $b s p R$ (BPSL1105), which, when disrupted led to a reduced level of expression of genes in the T3SS-3 locus as shown by microarray and real time PCR (Sun et al., 2010). bspR signals through the membrane bound regulator $\operatorname{bprP}$ (BPSS1553) which controls expression levels of both structural and secreted components of T3SS-3 (Sun et al., 2010). $b p r P$ further signals through $b s a N$ (BPSS1546) and its co-activator, the chaperone bicA (BPSS1533), controlling transcription of the known effectors bopC, bopE and $\operatorname{bopA}$, as well as the chaperone bicP (BPSS1523) and the regulators bprB-D (BPSS1520-22) (Sun et al., 2010; Chen et al., 2014). $b s a N$ also relays the regulation signal to the virulenceassociated Type 6 secretion system and virulence factors such as bimA and virAG (Sun et al., 2010; Chen et al., 2014).

The presence of genes allowing for arabinose assimilation was one of the first methods used to differentiate between virulent $B$. pseudomallei and avirulent B. thailandensis (Smith et al., 1997; Moore et al., 2004). Expressing the B. thailandensis arabinose assimilation operon in B. pseudomallei causes a down-regulation of expression of the T3SS-3 genes, notably the T3SS regulator $b s a N$, and also results in a reduction in virulence in a Syrian hamster model of infection (Moore et al., 2004). This suggests that loss of the arabinose assimilation operon may account for some of the differential virulence observed between these two species of Burkholderia (Moore et al., 2004).

\section{STRUCTURE OF T3SS-3}

The structure of the T3SS is well conserved and is similar to that of the bacterial flagella system (Kubori et al., 1998; Young et al., 1999; Gophna et al., 2003). It is thought that the flagella and the T3SS evolved from a similar ancestor, but the T3SS has been the product of a large amount of horizontal gene transfer (Gophna et al., 2003). T3SSs are separated into seven different families named after the archetype system in each family, each with slight differences in structure and host cell target, with multiple types of T3SS present in some bacterial species (e.g., plant or animal) (reviewed by Büttner, 2012). In recent years the structure of the Salmonella T3SS has been solved using cryo-EM (Schraidt and Marlovits, 2011) and cryo-ET (Hu et al., 2017). The structure of the Salmonella T3SS (reviewed by Galán et al., 2014) consists of inner and outer membrane rings connected by a rod, the extracellular needle and a secreted translocation pore which 


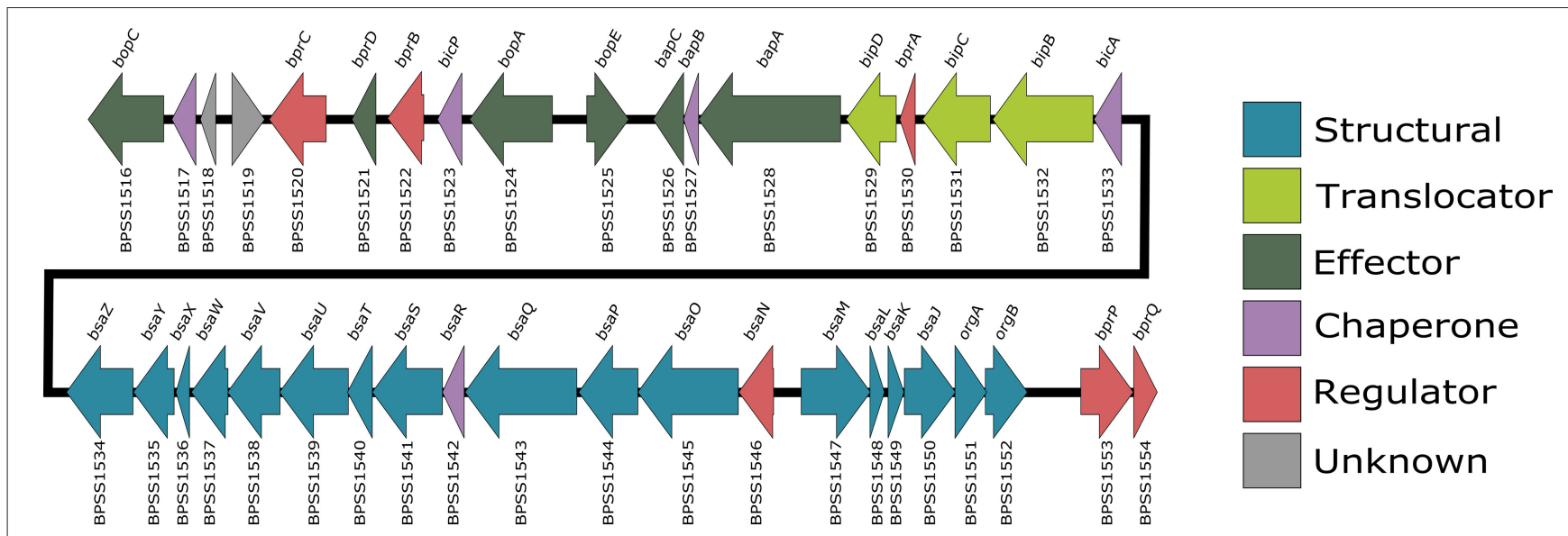

FIGURE 1 | B. pseudomallei K96243 T3SS-3 gene locus. Also known as the bsa locus, the T3SS-3 genes are encoded by chromosome 2 (BPSS1516-BPSS1554). Arrows which point right represent genes encoded on the forward strand and arrows which point left represent genes encoded on the reverse strand. Gene locus tags are listed below each arrow and gene names are listed above. The arrows are color coded according to their predicted function.

spans the target cell membrane. Assembly of the T3SS appears to be hierarchical and is the subject of multiple recent reviews (Büttner, 2012; Diepold and Wagner, 2014). Based on evidence from Yersinia and Salmonella, it appears construction of the T3SS begins with the formation of the outer-membrane/structural ring (Secretin) and independently the inner membrane export machinery, which are then linked by YscJ (Yersinia) or PrgK (Salmonella), followed by assembly of the ATPase/C-ring and the formation of the mature needle complex (Diepold et al., 2010, 2011; Wagner et al., 2010). The structural proteins in the B. pseudomallei T3SS-3 (Figure 2) that have been studied specifically are described below.

\section{Components of the Export Apparatus BsaZ (BPSS1534)}

BsaZ (BPSS1534) is a structural component with homology to SpaS of Salmonella (Stevens et al., 2002). SpaS is a component of the export apparatus and has been shown to undergo auto-cleavage causing a switch between secretion of structural components (early substrates) to secretion of the needle complex and translocator proteins (intermediate substrates) (Zarivach et al., 2008). B. pseudomallei bsaZ mutants are unable to secrete effector and translocator proteins (Stevens et al., 2003; Muangman et al., 2011; Vander Broek et al., 2015). Mutations in $b s a Z$ result in a significant delay in escape from the phagosome and reduced intracellular survival in J774.2 cells (Stevens et al., 2002; Burtnick et al., 2008). bsaZ mutants are also attenuated in murine (Stevens et al., 2004; Burtnick et al., 2008) and Syrian hamster (Warawa and Woods, 2005) models of melioidosis. bsaZ mutants have proven to be a useful tool in understanding the role of T3SS-3 in B. pseudomallei pathogenesis, however, the effect of these mutations other than an inability to secrete effector proteins is not well understood. For example, it is unclear if BsaZ undergoes auto-cleavage and is involved in secretion hierarchy in a similar manner to SpaS. It has also not been determined if $b s a Z$ mutants still assemble the external needle appendage, or at what stage in formation of the mature T3SS complex they are impaired.

\section{BsaQ (BPSS1543)}

Another component of the export apparatus of the B. pseudomallei T3SS-3 that has been described is BsaQ (BPSS1543), which is homologous to InvA from Salmonella (Sun et al., 2005). InvA is required for the formation of the mature T3SS in Salmonella as well as secretion of effector proteins (Kubori et al., 2000). bsaQ mutants display a similar phenotype to other T3SS-3 structural mutants in that they are delayed in phagosome escape, resulting in reduced intracellular survival (Muangsombut et al., 2008). The bsaQ mutants are unable to secrete the effector protein BopE or translocator tip protein $\mathrm{BipD}$, and show significant defects in cell invasion (Muangsombut et al., 2008). Similarly to BsaZ, there is a gap in our knowledge of whether BsaQ truly functions in a manner similar to InvA.

\section{Inner Membrane Ring BsaM (BPSS1547)}

The inner membrane component BsaM (BPSS1547) is homologous to Salmonella $\mathrm{PrgH}$, which forms the inner membrane ring of the Salmonella T3SS and is required for secretion of effector proteins (Kubori et al., 2000; Marlovits et al., 2004). A B. pseudomallei bsaM mutant induced lower levels of NF- $\kappa$ B signaling in HEK 293T cells when compared to the isogenic parent strain (Teh et al., 2014). The bsaM mutant activated NF- $\kappa \mathrm{B}$ at time points corresponding to a delayed escape from the phagosome, suggesting it has similar effects to the other T3SS-3 structural knockouts (Teh et al., 2014).

\section{Needle Components BsaL (BPSS1548)}

A crystal structure of the protein BsaL (BPSS1548) demonstrated significant structural similarity with $\mathrm{MxiH}$ (Shigella) and PrgI (Salmonella), which form the external needle structure (major needle subunit) of the T3SS (Zhang et al., 2006; Wang et al., 2007; Barrett et al., 2008). BsaL is recognized by the host cell neuronal inhibitory protein (NAIP) leading to activation of the NLRC4 inflammasome (Yang et al., 2013). NLRC4 has been shown to 


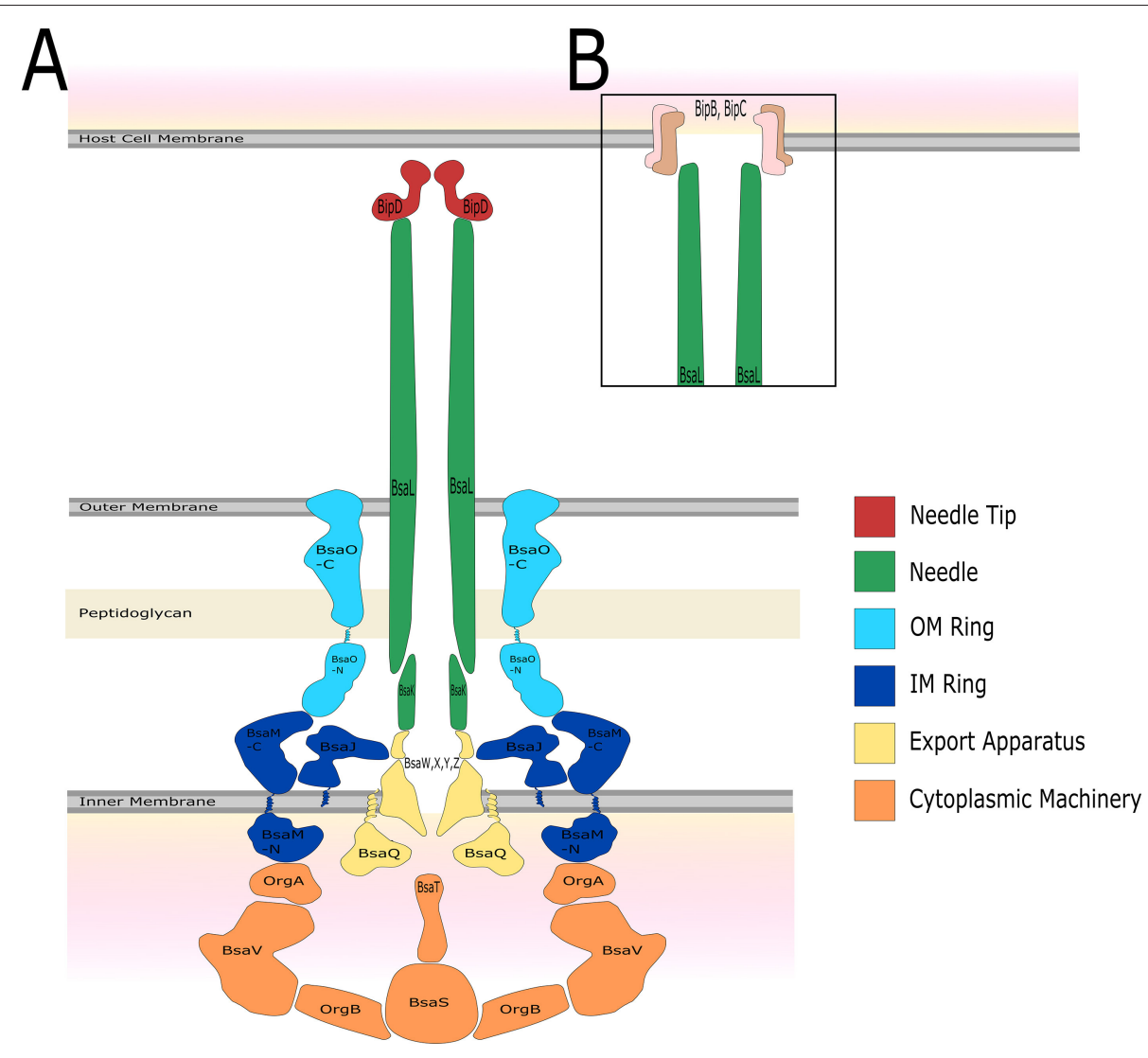

FIGURE 2 | The predicted structure of the B. pseudomallei K96243 T3SS-3 based on Salmonella SPI-1. The name of the protein which is predicted to constitute each structural component, as well as colors to represent different portions of the T3SS structure, are shown. (A) Before host cell contact, the T3SS is fully assembled spanning both the inner and outer bacterial membrane. The needle forms a channel extending out of the bacterium which is capped by the needle tip protein. (B) After contact with the host cell, a signal is relayed through the T3SS and translocator proteins form a pore in the host cell membrane allowing for injection of bacterial effector proteins.

be important in a murine model of respiratory melioidosis and a human NLRC4 polymorphism is associated with survival in melioidosis patients (West et al., 2014).

\section{BsaK (BPSS1549)}

The cellular protein Nod-like receptor NLRC4 recognizes T3SS minor needle component proteins from a range of Gram-negative bacteria, including BsaK (BPSS1549) from $B$. pseudomallei, activating an innate immune response through casapase-1 (Miao et al., 2010; Zhao et al., 2011; Bast et al., 2014). A B. pseudomallei bsaK mutant was highly attenuated in an intranasal murine model of melioidosis (Bast et al., 2014).

\section{Non-structural Proteins BsaU (BPSS1539)}

BsaU (BPSS1539) is homologous to InvJ from Salmonella which is the "molecular ruler" which determines the length of the T3SS needle (Kubori et al., 2000). Mutation of bsaU in B. pseudomallei resulted in delay in phagosome escape and reduced virulence in a BALB/c intranasal mouse infection model (Pilatz et al., 2006). The mutant was also deficient in its ability to secrete the effector protein BopE and the translocator tip protein BipD (Pilatz et al.,
2006). It can be hypothesized that without BsaU, the needle complex of T3SS-3 forms incorrectly, accounting for the lack of effector and translocator secretion.

\section{BsaP (BPSS1544)}

A family of T3SS proteins called the "gatekeeper" proteins (InvE/MxiC/SepL/YopN-TyeA) are involved in the control of effector and translocator protein secretion and the switch from intermediate to late substrates for secretion in Salmonella/Shigella/E. coli/Yersinia, respectively (reviewed in Büttner, 2012). These proteins are involved in the temporal regulation of their respective T3SSs and deletion of all of these proteins causes an increase in levels of secreted effectors, but has differing effects on the secretion of translocators. For example deletion of invE (Kubori and Galán, 2002) and sepL (Kresse et al., 2000; Deng et al., 2004, 2005) causes a reduction in translocator secretion, deletion of mxiC (Botteaux et al., 2009) has no effect on translocator secretion, and deletion of yopN (Forsberg et al., 1991; Iriarte et al., 1998) increases levels of secreted translocators. The closest homolog to this family of proteins in B. pseudomallei is BsaP (BPSS1544), which we have demonstrated functions as 
a gatekeeper protein for effectors in a manner most similar to Salmonella invE (Vander Broek et al., 2015). Deletion of bsaP creates a phenotype in which effector proteins are hyper-secreted with a concomitant decrease in translocator secretion (Vander Broek et al., 2015). Further studies are warranted to determine the molecular interactions of BsaP with other components of the T3SS-3, in order to fully understand BsaP in the context of the other members of the gatekeeper family of proteins.

\section{Structural Components for Which No Data Is Available}

Proteins for which no published work is available are OrgA (BPSS1551), OrgB (BPSS1552), BsaJ (BPSS1550), BsaO (BPSS1545), BsaT (BPSS1540), BsaV (BPSS1538), BsaW (BPSS1537), BsaX (BPSS1536), and BsaY (BPSS1535). The putative function of these proteins can be found in Table 2 and their predicted location in the structure of T3SS-3 is shown in Figure 2.

T3SS-3 has been well studied in terms of its role in virulence however very little has been reported on the structure and the molecular interactions between individual components of the T3SS itself. Determining the finer points of structure and hierarchy of assembly represent a major unanswered research question in terms of understanding T3SS-3 in the context of other well studied T3SSs.

\section{ENERGIZING SECRETION AND UNFOLDING OF SUBSTRATES}

Proteins are secreted in an unfolded state due to the narrow width of the needle channel which is $2-3 \mathrm{~nm}$ in S. flexneri (Blocker et al., 2001; Radics et al., 2014). This was proven by cryo-EM imaging of a substrate which was engineered to become trapped in the secretion channel (Radics et al., 2014). The ATPase at the base of the secretion system has been shown to dissociate proteins from their chaperones and is also thought to be involved in unfolding of the protein (Akeda and Galán, 2005). The source of energy for exporting proteins is the subject of some debate. In the flagellar T3SS of Yersinia and Salmonella, secretion can take place in the absence of the ATPase (Wilharm et al., 2004; Erhardt et al., 2014). This evidence, combined with a study which showed flagellar T3S was halted in the absence of a proton gradient, has led to the hypothesis that the ATPase is primarily required for protein unfolding and that proton motive force energizes secretion of the unfolded substrate (Paul et al., 2008).

The B. pseudomallei T3SS-3 ATPase is BsaS (BPSS1541). A B. pseudomallei bsaS mutant was unable to secrete the known effector protein BopE, demonstrated a defect in intracellular survival in RAW264.7 cells and was attenuated in BALB/c mice infected intra-nasally, demonstrating that the ATPase is required for T3S of effector proteins and has a similar phenotype to other T3SS-3 structural mutants (Gong et al., 2015). This agrees with a previous study in which $B$. pseudomallei and B. thailandensis containing in-frame deletions in $b s a S$, were impaired in their ability to escape the endosomal compartment and form plaques in host cell monolayers as a result of cell-to-cell spread (French et al., 2011). Salmonella lacking a functional ATPase will still assemble a mature T3SS, and will still secrete effector proteins, though at a reduced level (Erhardt et al., 2014). The effect that a bsaS mutation in B. pseudomallei T3SS-3 may have on either assembly of the T3SS apparatus or the secretion of early/middle substrates, such as the major needle component (BsaL) and the needle tip protein (BipD) remains an interesting open question.

\section{NEEDLE TIP AND TRANSLOCATOR PROTEINS-SENSING HOST CONTACT}

Upon host cell contact, the translocators of the T3SS are inserted into the host cell membrane forming a pore through which effector proteins may pass. Shigella is able to lyse red blood cells by inserting the translocators $\mathrm{IpaB}$ and $\mathrm{IpaC}$ into the RBC membrane forming a 25 angstrom pore (Blocker et al., 1999). Secretion of the translocator proteins is controlled by the needle tip protein. A Shigella needle tip protein mutant (ipaD), constitutively secreted the translocators IpaB and IpaC (Picking et al., 2005). Immunofluorescence microscopy demonstrated the presence of the Shigella IpaD protein on the surface of the bacteria in the absence of a host cell membrane, a finding that was further confirmed by electron microscopy (Espina et al., 2006). The needle tip protein probably acts to sense host cell contact, inhibiting premature secretion of translocators (Espina et al., 2006). In the same study it was shown that antibodies to the tip protein disrupted the haemolysis of sheep erythrocytes indicating the functional importance of IpaD in the insertion of the translocator complex into eukaryotic cell membranes, as well as regulating effector protein secretion (Espina et al., 2006). Next, the T3SS senses host cell contact when IpaD binds to bile salts causing IpaB to be exposed at the needle tip (Olive et al., 2007; Stensrud et al., 2008).

The final step in secretion of the translocation pore is dependent on Shigella interacting with host cell lipids to induce IpaC secretion (Epler et al., 2009). When cultured in the presence of liposomes, IpaC localizes to the bacterial surface and is secreted (Epler et al., 2009). This agrees with earlier evidence that cholesterol is bound by translocation components (Salmonella SipB and Shigella IpaB), is important for entry into host cells and is required for efficient translocation of effector proteins into host cells (Lafont et al., 2002; Hayward et al., 2005). There is some evidence to suggest that the translocator proteins, along with the needle tip and a functional T3SS, may be sufficient to determine the intracellular niche of Salmonella and Shigella in the absence of any of the effector proteins (Du et al., 2016).

\section{BipD (BPSS1529)}

BipD (BPSS1529) is the needle tip protein of the B. pseudomallei T3SS-3. It is homologous to SipD (Salmonella), IpaD (Shigella), and LcrV (Yersinia). BipD has been confirmed to be secreted by the B. pseudomallei T3SS-3 (Stevens et al., 2003; Vander Broek et al., 2015). The crystal structure of BipD was solved (Erskine et al., 2006; Knight et al., 2006; Roversi et al., 2006; Johnson et al., 2007; Pal et al., 2010) and the 3-dimensional 
TABLE 2 | B. pseudomallei T3SS-3 genes, corresponding proteins and predicted functions.

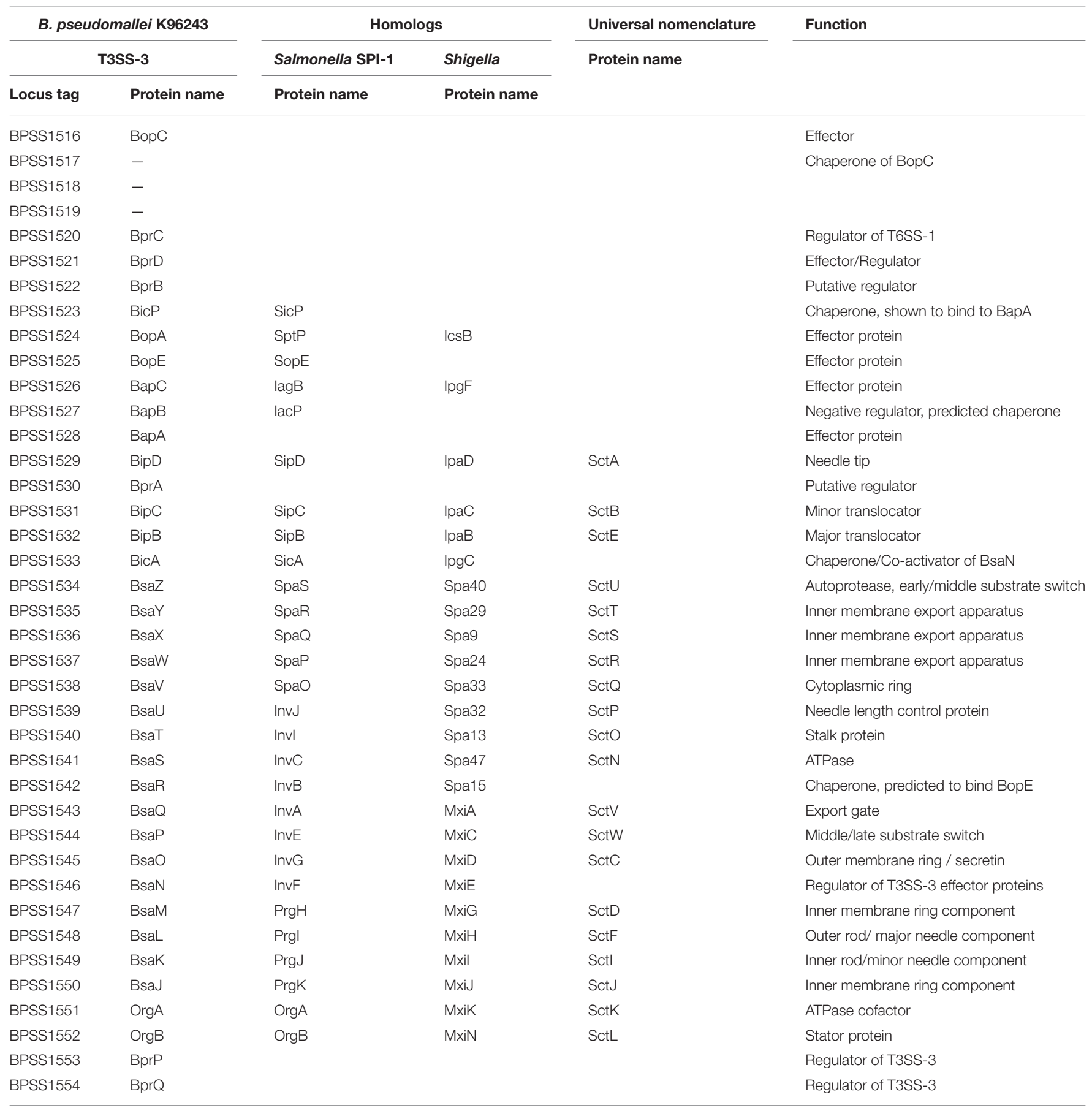

Homologs from Salmonella SPI-1 and Shigella are given for reference. Where applicable, the universal nomenclature for T3SS structural proteins is also listed.

structure is highly similar to IpaD of Shigella (Johnson et al., 2007) and Salmonella SipD (Espina et al., 2007), but bipD cannot functionally complement sipD in Salmonella (Klein et al., 2017). It was demonstrated that the structure of BipD, as well as $\mathrm{IpaD}$ and $\mathrm{SipD}$, is dependent on $\mathrm{pH}$ changes (Markham et al., 2008). Interestingly when cultured in a more acidic $\mathrm{pH}$ of $4.5, B$. thailandensis secretes increased amounts of
BipD as well as BopE (Jitprasutwit et al., 2010), though the study also described amino acid differences between BipD of B. pseudomallei and B. thailandensis (Jitprasutwit et al., 2010), raising the question as to what effect $\mathrm{pH}$ may have on T3SS-3 in B. pseudomallei.

In a B. pseudomallei bipD mutant, the levels of both translocators and effectors secreted into the culture supernatant 
are increased (Stevens et al., 2003; Vander Broek et al., 2015), in agreement with data published for the homologous Shigella protein IpaD (Parsot et al., 1995; Picking et al., 2005). IpaD blocks secretion of effector proteins until host cell contact has taken place (Roehrich et al., 2013), and because of its similarity in both sequence and structure (Erskine et al., 2006) it is perhaps unsurprising that $\mathrm{BipD}$ would function in a similar manner. More recent evidence suggests that Shigella IpaD may be involved in controlling the secretion of translocator and effector proteins through an interaction with the gatekeeper protein MxiC (Roehrich et al., 2016). This would suggest an interaction between BipD and BsaP in B. pseudomallei which may have a similar activity.

Needle tip proteins are of particular interest because of their potential use as subunit vaccines. Most notably the Yersinia pestis needle tip protein LcrV (V antigen), especially when combined with the Fraction 1 (F1) protein, is an effective vaccine that has been tested in human clinical trials (reviewed by Williamson, 2009). Vaccination of mice with the Shigella needle tip protein $\mathrm{IpaD}$, along with the translocator IpaB, induced high levels of protection upon subsequent challenge (Martinez-Becerra et al., 2012, 2013; Heine et al., 2013). Some 15 years ago, it was described that convalescent serum from a melioidosis patient reacted specifically with a recombinant GST-tagged BipD protein (Stevens et al., 2002). CD4+ T cells taken from mice infected with an attenuated strain of $B$. pseudomallei showed specificity for BipD (Haque et al., 2006). Similarly, human monocytederived dendritic cells from healthy $B$. pseudomallei seropositive donors were pulsed with purified BipD after which CD4+ T cells were able to recognize the recombinant protein (Tippayawat et al., 2011). A B. pseudomallei bipD mutant was significantly attenuated in a $\mathrm{BALB} / \mathrm{c}$ intranasal murine infection model, demonstrating the importance of this protein in vivo (Stevens et al., 2004). Attempts have been made to use BipD as a recombinant subunit vaccine in a $\mathrm{BALB} / \mathrm{c}$ murine intraperitoneal model of infection, but in both studies the vaccine showed no protection upon subsequent challenge (Stevens et al., 2004; Druar et al., 2008).

\section{BipB (BPSS1532)}

BipB (BPSS1532) shares $46 \%$ amino acid identity with the Salmonella translocator protein SipB, and is secreted by T3SS3 in a bsaZ dependant manner (Vander Broek et al., 2015). In a Salmonella $\operatorname{sip} B$ mutant, $\operatorname{bip} B$ is unable to complement $\operatorname{sip} B$ demonstrating evolutionary separation of these proteins (Klein et al., 2017). This is an important reminder that although T3SSs are similar in structure, T3SS proteins do not always function identically.

A B. pseudomallei K96243 bipB insertion mutant showed reduced invasion and cell-to-cell spread in HeLa cells, and a reduced ability to form multi-nucleated giant cells in J774 cells (Suparak et al., 2005). In vivo, in BALB/c mice infected intranasally, the $\operatorname{bip} B$ mutant was greatly attenuated and showed a phenotype similar to that of the bipD translocator mutant (Stevens et al., 2004; Suparak et al., 2005). This is likely due to the inability of the T3SS to function correctly without the formation of the translocation pore, and any proposed secondary function would require further investigation. The N-terminal region of BipB has been tested as a protective antigen in a murine model of melioidosis, but as with BipD, showed no protection upon subsequent challenge (Druar et al., 2008).

\section{BipC (BPSS1521)}

BipC (BPSS1531) is a homolog of the Salmonella SipC and Shigella IpaC translocator proteins. The Salmonella SipC protein has been shown to interact with $\mathrm{SipB}$ to form the translocon pore (Myeni et al., 2013). Beyond their role as a translocator protein, SipC and IpaC also function as effector proteins within the eukaryotic cell. SipC has actin nucleation activity and bundles F-actin (Hayward and Koronakis, 1999). The ability of SipC to nucleate and bundle F-actin as well as form the translocation pore, are all dependant on the C-terminal 209 amino acids of the 409 amino acid protein (Hayward and Koronakis, 1999; Chang et al., 2005; Myeni and Zhou, 2010). Actin bundling appears to be important for cell invasion, as Salmonella containing a sipC mutation abolishing its actin bundling activity, but not translocator function, was less invasive than the parental strain (Myeni and Zhou, 2010). Internalization of B. pseudomallei can be blocked by the actin polymerization inhibitor cytochalasin $\mathrm{D}$ (Jones et al., 1996), indicating the importance of actin cytoskeletal rearrangements in the uptake of $B$. pseudomallei. Similarly to $\mathrm{SipC}, \mathrm{BipC}$ is also able to polymerise actin in vitro and stabilizes F-actin indicating possible actin bundling activity (Kang et al., 2016a and our own unpublished observations). Interestingly, Salmonella SipA protein enhances the ability of SipC to nucleate and bundle F-actin (McGhie et al., 2001), but a homolog of SipA is not encoded by the genome of B. pseudomallei. SipC has also been shown to bind to host Syntaxin 6 and thereby recruit LAMP1 to the Salmonella containing vacuole (SCV), helping to stabilize its membrane (Madan et al., 2012). The functional relevance of the actin-binding activity of BipC and whether it binds any other host cell proteins requires further study.

In Salmonella and Shigella, the SipC/IpaC family of translocator/effector proteins may play a crucial role in determining the intracellular niche of the bacteria. There is evidence to suggest that sipC and ipaC cannot fully complement each other (Osiecki et al., 2001; Klein et al., 2017). The authors suggest the proteins, while both translocators, may have some divergent functions which may parallel the different intracellular lifestyles of the pathogens, with Salmonella residing within the vacuole and Shigella rapidly escaping into the cytosol (Osiecki et al., 2001). This is supported by a recent study in which Salmonella expressing ipaC, was shown to be capable of vacuole escape (Du et al., 2016). Because of closer parallels between the intracellular lifestyles of B. pseudomallei and Shigella, we would predict that BipC would function in a manner more similar to IpaC than SipC, mediating the exit of the bacterium from the endocytic compartment into the host cell cytosol. In a Salmonella sipC mutant, bipC is unable to complement sipC (Klein et al., 2017), further supporting a possible difference in accessory function of these proteins.

The C-terminal and N-terminal regions of $\mathrm{BipC}$ have previously been separately tested as a protective antigen in mice, but neither antigen showed any protection upon challenge with 
B. pseudomallei (Druar et al., 2008). In another study, a $B$. pseudomallei bipC mutant showed reduced cell adhesion and invasion of A549 cells (Kang et al., 2015). This bipC mutant also showed a delay in escape from the phagosome, leading to a delay in formation of actin tails in the host cell cytoplasm and intracellular replication (Kang et al., 2015). The mutant was also attenuated in BALB/c mice infected intraperitoneally (Kang et al., 2015). The transcriptome of livers of mice infected with the bipC mutant showed a lower expression of genes involved in actin cytoskeleton signaling, MAPK signaling, integrin signaling and TNF when compared to mice infected with the parental B. pseudomallei strain (Kang et al., 2016b). While this shows the importance of $\mathrm{BipC}$ in virulence, both in vivo and in vitro, it does not separate the role of BipC as a translocator necessary for a functional T3SS and rapid escape from the endosome, from its role as an effector protein.

\section{SECRETION SIGNALS AND CHAPERONES}

Type III secretion signals are located at the N-terminus of a protein, are not cleaved and do not share primary sequence identity with each other (Michiels and Cornelis, 1991; Schesser et al., 1996). In Yersinia, it was demonstrated that as little as 15 amino acids of the $\mathrm{N}$-terminus of YopE were required for secretion (Sory et al., 1995). Interestingly, substituting the alanines at position 2 and 15 in the YopE secretion signal with glutamic acid, did not affect secretion (Anderson and Schneewind, 1997). Even shifting the reading frame did not prevent the secretion of YopE, which the authors suggested may indicate a secretion signal located in the mRNA encoding the effector protein (Anderson and Schneewind, 1997).

A second important signal in the $\mathrm{N}$-terminal region of T3SS effector proteins is the chaperone binding domain (CBD) which is required for the specific secretion of effector proteins (Abe et al., 1999; Ehrbar et al., 2003, 2006; Lee and Galán, 2003, 2004) as well as for their stability in the bacterial cytoplasm (FrithzLindsten et al., 1995; Abe et al., 1999). By determining the crystal structure of an effector protein bound to its chaperone, it is known that T3SS chaperones in Yersinia and Salmonella bind the N-terminal amino acids of their effector protein, just after the T3S signal, but before any functional domains, and maintain the bound effector protein in a partially unfolded state that may be more competent for secretion (Birtalan and Ghosh, 2001; Stebbins and Galán, 2001).

The T3S signal also appears to be promiscuous between systems, allowing secretion of effector proteins from bacteria in an unrelated host bacterium containing a T3SS (Rossier et al., 1999; Hovis et al., 2013). This is even true of less similar T3SSs, as demonstrated by the ability of the Hrp Plant T3SS of Xanthomonas to secrete the mammalian effector protein Yersinia YopE (Rossier et al., 1999). Perhaps because of the similarity between the two, virulence-associated T3SS effectors can be secreted by the bacterial flagellar T3SS system in Yersinia and Salmonella (Young and Young, 2002; Lee and Galán, 2004; Warren and Young, 2005; Ehrbar et al., 2006). It is only through interaction with the appropriate chaperone that specific secretion through a single system is achieved. Inhibition of the ability of Salmonella SopE to bind its chaperone InvB, caused secretion through both the flagellar and SPI-1 virulence associated T3SS (Lee and Galán, 2004; Ehrbar et al., 2006). The genome of $B$. pseudomallei encodes five putative T3SS-3 chaperones, though little work concerning their function has yet been described.

\section{BPSS1517}

The protein encoded by the gene BPSS1517 is predicted to be a putative chaperone (Panina et al., 2005) and has been shown to interact with the downstream effector protein BopC (BPSS1516) (Muangman et al., 2011).

\section{BicP (BPSS1523)}

BicP (BPSS1523) shares homology with Salmonella SicP, a specific chaperone for the effector protein SptP (Fu and Galán, 1998). The closest homolog to SptP in B. pseudomallei is BopA (BPSS1524) which was predicted to be the binding partner for BicP (Panina et al., 2005), but the interaction between the two proteins has not formally been demonstrated.

\section{BapB (BPSS1526)}

BapB (BPSS1526) is homologous to Salmonella IacP (Stevens et al., 2002). IacP is important for Salmonella invasion into host cells by playing a role in regulating SopA, SopB and SopD secretion (Kim et al., 2011). Formerly considered a possible candidate effector protein, BapB was not found to be secreted by T3SS-3 (Treerat et al., 2015; Vander Broek et al., 2015). Deletion of $b a p B$ caused an increase in the transcription and secretion of BopE, indicating it may be a negative regulator of effector transcription (Treerat et al., 2015). In the same study the authors performed a phylogenetic analysis which suggested that BapB may be closely related to the Salmonella FliT chaperone protein (Treerat et al., 2015).

\section{BicA (BPSS1533)}

BicA (BPSS1533) is homologous to the Salmonella chaperone SicA. SicA binds to and prevents the association and resulting degradation of SipC and SipB in the bacterial cytoplasm (Tucker and Galán, 2000). As SipC is secreted by a mature needle complex, SicA is freed and interacts with the transcriptional regulator InvF to increase the expression of effector proteins (Tucker and Galán, 2000; Darwin and Miller, 2001). B. pseudomallei BicA is required for the secretion of the known effector proteins BopE and BopA (Sun et al., 2010), and BicA along with the regulator BsaN activate transcription of T3SS3 effector proteins, translocators and chaperones (Chen et al., 2014). The bicA gene is also able to partially complement a Salmonella sicA mutant (Klein et al., 2017), further supporting a homologous function. BicA is required for respiratory melioidosis in mice (Gutierrez et al., 2015b).

\section{BsaR (BPSS1542)}

BsaR (BPSS1542) is homologous to the Salmonella chaperone InvB which has been shown to be required for secretion of the effector proteins SopE and SopA (Ehrbar et al., 2003, 2004; Lee and Galán, 2003). BsaR is predicted to be the chaperone for BopE using a computational screen for chaperones in B. pseudomallei 
K96243 (Panina et al., 2005), although this has not yet been experimentally validated.

\section{T3SS-3 EFFECTOR PROTEINS}

The role of the T3SS is to deliver an array of effector proteins into the target cell to subvert host cell functions. The function of different effector proteins is extremely varied, ranging from blocking apoptosis (E. coli NleH) (Hemrajani et al., 2010), prevention of phagocytosis (Yersinia YopH) (Persson et al., 1997), cytotoxic activity (Pseudomonas aeruginosa ExoU) (Sato et al., 2003) and disruption of the actin cytoskeleton (Salmonella SopE) (Hardt et al., 1998). B. pseudomallei encodes seven effector proteins known to be secreted by T3SS-3 (CHBP, BopC, BopA, BapA, BprD, BapC, and BopE), as well as one hypothetical T3SS effector BopB (Pumirat et al., 2014; Vander Broek et al., 2015).

\section{CHBP/Cif (BPSS1385)}

CHBP (BPSS1385) is a homolog of E. coli cell cycle inhibiting factor (Cif) and is the only identified T3SS-3 effector protein that is encoded outside of the T3SS-3 locus. Cif and CHBP are able to deamidate cellular NEDD8 causing cell cycle arrest (Nougayrède et al., 2001; Cui et al., 2010) and CHBP causes cell cycle arrest when expressed in B. thailandensis (Cui et al., 2010). CHBP has also been shown to activate the cellular kinase ERK independent of its ability to deamidate NEDD8 (Ng et al., 2017).

The gene encoding CHBP is present in $\sim 76 \%$ of the available $B$. pseudomallei genomes and a Western blot assay used to probe for the presence of the CHBP protein in B. pseudomallei clinical isolates from the endemic region detected CHBP in $47 \%$ of isolates tested (Pumirat et al., 2014). Interestingly, CHBP is not secreted under standard growth conditions, but $B$. pseudomallei secretes CHBP in U937 cells in a bsaQ-dependent manner (Pumirat et al., 2014). A B. pseudomallei K96243 chbP insertion mutant was impaired in its ability to form plaques in HeLa cells at $24 \mathrm{~h}$ and demonstrated lower cytotoxicity at $6 \mathrm{~h}$ as assessed by LDH release assays (Pumirat et al., 2014). Both phenotypes could be complemented by expression of chbP in trans indicating that these phenotypes were due to disruption of the $c h b P$ gene and not due to unexpected polar effects of the insertion mutation (Pumirat et al., 2014).

\section{BopB/FolE (BPSS1514)}

BopB (BPSS1514) or FolE, is annotated to be a GTP cyclohydrolase I and was thought to be a candidate effector protein (Stevens et al., 2004). Yet a bopB mutant did not display a significantly reduced time to death in a $\mathrm{BALB} / \mathrm{c}$ intraperitoneal infection model (Stevens et al., 2004). Similarly, mutation of bopB did not affect invasion and intracellular replication of host cells (Chen et al., 2014). Expression of bopB is co-regulated with the other T3SS-3 effectors by BsaN, but the role BopB plays in infection is still unknown (Chen et al., 2014).

\section{BopC (BPSS1516)}

BopC (BPSS1516) is a 509 amino acid protein with no significant sequence homology to proteins from other species besides $B$. mallei. It is encoded just before the T3SS-3 locus along with
BPSS1517, its chaperone (Muangman et al., 2011). BopC was detected in the culture supernatants of WT B. pseudomallei 10276, but not in supernatants of a bsaZ insertion mutant, indicating that BopC is secreted by T3SS-3 (Muangman et al., 2011; Vander Broek et al., 2015). The first 20 amino acids of BopC fused to the $\beta$-lactamase gene TEM1, was sufficient for translocation into HeLa cells in a T3SS-dependant manner (Muangman et al., 2011). A B. pseudomallei K96243 bopC mutant was hindered in its ability to invade A549 cells (Muangman et al., 2011) and displayed reduced levels of intracellular survival (Srinon et al., 2013). The bopC mutant also demonstrated delayed phagosome escape in J774A.1 cells as shown by staining for colocalisation of the bacteria with the cellular lysosomal marker protein LAMP-1, which likely explains the defect in intracellular survival (Srinon et al., 2013).

\section{BprD (BPSS1521)}

BprD (BPSS1521) has no known homology to proteins outside of B. pseudomallei and the closely related Burkholderia species. It is labeled as a putative regulator of T3SS-3, though a knockout of the bpr operon (bprB-D) showed no effect on the expression of T3SS-3 genes (Sun et al., 2010). Its expression is regulated by $\mathrm{BsaN}$ along with the known effector proteins BopA, BopC and BopE (Sun et al., 2010; Chen et al., 2014) and bipD gene expression is significantly up-regulated in tissues of infected mice (Chirakul et al., 2014). The same study demonstrated attenuation of the bprD mutant in BALB/c mice infected intraperitoneally, which the authors speculate may be due to the up-regulation of the T6SS-1 through effects on $\operatorname{bprC}$ (Chirakul et al., 2014).

Our own work has demonstrated that BprD is secreted into the supernatant in a T3SS-3 bsaZ-dependant manner (Vander Broek et al., 2015). While this may seem surprising, it is not without precedent that a regulator of the T3SS is also a substrate for secretion, for example, Yersinia LcrQ (Cambronne et al., 2000). It is thought that LcrQ acts as a feedback inhibitor of the expression of Yersinia effectors (Cambronne et al., 2000). When LcrQ is secreted into host cells and the levels of LcrQ in the bacterium are depleted, inhibition is relieved and T3S can progress (Cambronne et al., 2000). Whether BprD is secreted into host cells, whether it acts as a true effector protein and the mechanisms by which it regulates virulence and T6S present interesting research questions for the field.

\section{BopA (BPSS1524)}

BopA (BPSS1524) shares 23\% amino acid identity with Shigella IcsB (Cullinane et al., 2008). It has been predicted to contain a Rho GTPase inactivation domain (RID) similar to that found in Vibrio cholerae VcRtxA and other MARTX toxins which indirectly inactivate Rho GTPases (Pei and Grishin, 2009). IcsB, along with its chaperone IpgA, are important for Shigella's ability to escape LC3-positive autophagosomes once inside the host cell, and this activity is dependent on the IcsB cholesterol-binding domain (Kayath et al., 2010; Campbell-Valois et al., 2015). BopA also contains a functional cholesterol-binding domain (Kayath et al., 2010). The B. pseudomallei homolog of IpgA is BicP, which co-purifies with BopA and helps to prevent its degradation, indicating that it is the chaperone for BopA (Kayath et al., 2010). 
BopA is secreted by T3SS-3 in a bsaZ-dependant manner (Vander Broek et al., 2015) and the first 58 amino acids of B. mallei BopA fused to the Yersinia enterolitica phospholipase YplA, has been shown to be secreted in a surrogate enteropathogenic E. coli host (Whitlock et al., 2008).

BopA is important for the intracellular survival of $B$. pseudomallei in phagocytic cells (Cullinane et al., 2008). A B. pseudomallei K96243 bopA mutant displayed reduced intracellular survival and an increased localisation with GFPLC3, an indicator of autophagy stimulation, in RAW 264.7 cells (Cullinane et al., 2008). This reduction in intracellular survival was overcome when cells were treated with the autophagy inhibitor wortmannin (Cullinane et al., 2008). Another study demonstrated that BopA is important for escape of the bacterium from the phagosome (Gong et al., 2011). A B. mallei ATCC 23344 bopA mutant demonstrated reduced intracellular survival in J774A.1 cells (Whitlock et al., 2008). Interestingly, in the murine alveolar macrophage cell line MH-S, the same $B$. mallei bopA mutant exhibited increased intracellular survival when compared to the isogenic parental strain, indicating that different cell types may rely on different mechanisms to control intracellular B. mallei (Whitlock et al., 2009). BALB/c mice infected intraperitoneally with a B. pseudomallei 576 bopA insertion mutant were significantly delayed in time to death when compared to the parental strain (Stevens et al., 2004). Similarly, $\mathrm{BALB} / \mathrm{c}$ mice infected intra-nasally with a B. mallei ATCC 23344 bopA insertion mutant also showed a delayed time to death. No bacteria were recovered from the lung tissue of animals infected with the bopA mutant while $10^{8}$ bacteria were recovered from the lungs of animals infected with B. mallei (Whitlock et al., 2009). In mice immunized with recombinant BopA and challenged intranasally with B. mallei ATCC23344 or B. pseudomallei 1026b, the BopA vaccine protected 100 and $60 \%$, respectively of animals 21 days post infection (Whitlock et al., 2010).

\section{BopE (BPSS1525)}

BopE (BPSS1525) is the best characterized of the B. pseudomallei effector proteins and is commonly used as a readout for the ability of the T3SS-3 to secrete effector proteins. BopE is $27 \%$ identical over a region of 168 amino acids to the Salmonella guanine nucleotide exchange factor (GEF) SopE (Stevens et al., 2003). BopE is secreted by B. pseudomallei in a manner dependent on the T3SS-3 (Stevens et al., 2003; Muangsombut et al., 2008; Vander Broek et al., 2015) and is required for efficient invasion of non-phagocytic cells (Stevens et al., 2003). Also, ectopic expression of BopE in HeLa cells causes significant actin cytoskeletal rearrangements with similarity to ectopic SipC expression (Stevens et al., 2003). Using fluorescence spectrometry, it was demonstrated that purified BopE, similar to SopE, is a functional GEF for both Rac1 and Cdc42, but with about 10 fold lower activity than SopE (Stevens et al., 2003). This lower activity may be explained by differences in the catalytic domains, as the SopE catalytic domain stays in an open conformation, while BopE adopts a closed conformation which requires interaction with $\mathrm{Cdc} 42$ to allow for GEF activity (Upadhyay et al., 2008). HEK 293T cells transfected with plasmids expressing BopE and caspase-1, resulted in increased activation of caspase- 1 and -7 (Bast et al., 2014). When the active site of the transfected BopE was mutated, levels of activation of caspase -1 and -7 returned to basal levels indicating BopE's GEF activity is required for the activation of caspase-1 and -7 (Bast et al., 2014).

BopE is a potent $\mathrm{T}$ cell antigen in mice (Haque et al., 2006) and in sero-positive recovered melioidosis patients (Tippayawat et al., 2009). However, in an intraperitoneal BALB/c murine model of melioidosis, ablation of the bopE gene did not affect the median time to death of the animals when compared to the parental strain (Stevens et al., 2004).

\section{BapC (BPSS1527)}

BapC (BPSS1526) is homologous to Salmonella IagB (Stevens et al., 2002). IagB is thought to be a lytic transglycosylase involved in the breakdown of the bacterial peptidoglycan layer, allowing connection of the inner and outer membrane components of the secretion system, though this function has not been formally demonstrated (Zahrl et al., 2005). BapC is secreted by T3SS3 in a manner dependant on bsaS (Treerat et al., 2015). A B. pseudomallei K96243 bapC mutant showed a slight attenuation in a competitive growth assay in an acute BALB/c model of infection (Treerat et al., 2015), whereas a B. pseudomallei 1026b bapC mutant showed no significant attenuation in a Syrian hamster model of melioidosis (Warawa and Woods, 2005).

\section{BapA (BPSS1528)}

BapA (BPSS1528) has no known homology to any other bacterial or host cell proteins except the BapA orthologues of $B$. pseudomallei and the closely related species $B$. thailandensis and B. mallei. BapA is secreted by T3SS-3 in both a BsaS and BsaZ dependant manner (Treerat et al., 2015; Vander Broek et al., 2015). A 1026b B. pseudomallei bapA mutant showed no attenuation in a Syrian hamster model of infection (Warawa and Woods, 2005), whereas a B. pseudomallei K96243 bapA mutant was attenuated in a competitive growth assay in an acute BALB/c model of infection (Treerat et al., 2015).

\section{FUTURE PERSPECTIVES}

While there has been a wealth of new information concerning B. pseudomallei T3S, there are still many significant gaps in knowledge, particularly with regard to the importance of T3SS-1 and T3SS-2 in melioidosis. It is possible that the plant pathogenlike T3SS-1 and T3SS-2 add fitness to B. pseudomallei in the environment, allowing infection/colonization of adjacent plant life. However, it is also possible that these systems are relevant in mammalian hosts, given their conservation amongst the $B$. pseudomallei strains sequenced to date, and the finding that T3SS-1 is required for full virulence in a murine model of melioidosis (D'Cruze et al., 2011).

It is still unclear whether T3SS-3 plays a significant role in invasion of host cells, particularly non-phagocytic cells. There have been many reports of T3SS-3 or its effector proteins playing a role in invasion (Stevens et al., 2003; Suparak et al., 2005; Muangsombut et al., 2008; Muangman et al., 2011; Kang et al., 2015). Yet in another study, T3SS-3 ATPase (bsaS) mutants did not show a decrease in invasion efficiency in HEK293 or HeLa cells (French et al., 2011). This observation is important because 
it questions the involvement of T3SS-3 in invasion as well as highlighting a general lack of understanding of the pathways and mechanisms involved in B. pseudomallei entry into host cells.

To date CHBP is the only effector protein secreted by the B. pseudomallei T3SS-3 that is encoded outside of the T3SS3 locus, and which is not present in the genome of all strains (Pumirat et al., 2014). This raises the question of whether other effector proteins secreted by T3SS-3, but encoded outside of the T3SS-3 locus, may be present in other strains. Full genome comparisons of almost 100 strains of $B$. pseudomallei identified $86 \%$ of genes as being conserved and present in all strains (Sim et al., 2008). The other $14 \%$ of genes, considered accessory genes, were disproportionally present in genomic islands and were associated with clinical isolates (Sim et al., 2008). The GIs in B. pseudomallei are highly variable between strains. A study of five clinical B. pseudomallei strains identified a total of 71 GIs distributed between the strains, with at least half being unique to the strain in which they were identified (Tuanyok et al., 2008). The variability in these regions is largely due to horizontal gene transfer and B. pseudomallei has a relatively high rate of lateral gene transfer compared to the mutation rates of other bacterial species (Pearson et al., 2009). As B. pseudomallei has a large amount of genomic diversity in its accessory genome and a high rate of lateral gene transfer, there is a strong possibility that other novel effector proteins are encoded in other strains of $B$. pseudomallei that have yet to be identified. Study of these effector proteins could provide important insights into strain differences as well as the potential for novel effector biology, but it is a difficult task as the secretome of B. pseudomalle $i$ is very complex (Vander Broek et al., 2015). Also, due to the temporal and hierarchical control of the T3SS, there is always the possibility that an effector protein will not be secreted under the conditions used in a given experiment (reviewed in Büttner, 2012). Previous methods of identifying T3SS-3 effector proteins have relied on initial bioinformatics prediction (Stevens et al., 2003; Muangman et al., 2011) or high throughput screens (Vander Broek et al., 2015), both of which may prove to be useful tools for further studies of B. pseudomallei T3S. Indeed it is timely to apply these approaches to the identification and characterization of effector proteins secreted by the lesser studied T3SS- 1 and T3SS-2.

Another important outstanding area of research is characterizing the functions of those effector proteins that have already been identified. One common characteristic of many T3SS effector proteins that complicates this task is their functional redundancy (reviewed in Galán, 2009). Commonly, deletion of one effector protein yields little or no phenotype in infection models because other effector proteins target either the same host cell protein or pathway (reviewed in Galán, 2009). In a biological system this would increase the chance of effectors successfully carrying out their intended function and decrease the likelihood of host cell interference. This functional redundancy also highlights the evolutionary importance of dysregulating specific cellular pathways from the standpoint of the bacterium. Even where redundancy does not exist, the function of effector proteins are often subtle when compared to bacterial toxins and may not be easily measurable in in vitro or in vivo models of infection (reviewed in Dean, 2011). This lack of a phenotype to inform focused studies presents a challenge for investigators, creating the need for high throughput "fishing" assays, such as protein immunoprecipitation/pulldowns and yeast two-hybrid assays. These assays have been used successfully to identify host cell binding partners and the subsequent functions of effector proteins from other bacteria (Zhou et al., 2013; Pallett et al., 2014). Understanding the functions of T3SS-3 effector proteins may provide new insights into host-pathogen interactions in B. pseudomallei infection.

Finally, the T3SS-3 has been shown to be one of the most important virulence factors in B. pseudomallei models of infection, raising the question of whether T3SS-3 could be a useful target for protective vaccines or therapeutic intervention in melioidosis patients. Although several attempts have been made to use live-attenuated vaccines based on mutation of key T3SS3 genes in murine models of melioidosis, none have proven to provide sterilizing immunity. Despite being a potent B- and Tcell antigen, attempts to utilize $\mathrm{BipD}$ as a subunit vaccine in murine models of melioidosis have shown little promise (Stevens et al., 2004; Druar et al., 2008). There have also been attempts to use the translocator proteins of T3SS-3 as subunit vaccines. The $\mathrm{N}$-terminal region of $\mathrm{BipB}$ was tested as a protective antigen in mice, but showed no protection against subsequent challenge (Druar et al., 2008). The C-terminal and $\mathrm{N}$-terminal regions of BipC have also been separately tested as a subunit vaccine in mice, but neither antigen showed any protection (Druar et al., 2008). Some studies have focused on the use of effector proteins as subunit vaccines. Out of these studies the BopA protein shows most promise, since mice immunized with recombinant BopA were protected against subsequent intranasal challenge with both B. mallei and B. pseudomallei (Whitlock et al., 2010). More recently interest in the use of small molecule inhibitors of the T3SS-3 has arisen (Gong et al., 2015). Treatment of $B$. pseudomallei infected RAW264.7 cells with a small molecule inhibitor targeting BsaS of the T3SS-3, resulted in a decrease in bacterial intracellular survival (Gong et al., 2015). However, the use of such inhibitors is still very much in its infancy, with important in vivo studies being required to determine whether such small molecules would be effective in murine models of melioidosis.

\section{AUTHOR CONTRIBUTIONS}

CV and JS contributed equally to the writing of this review article.

\section{ACKNOWLEDGMENTS}

The authors are supported by an Institute Strategic Programme Grant from the BBSRC. 


\section{REFERENCES}

Abe, A., De Grado, M., Pfuetzner, R. A., Sánchez-SanMartin, C., DeVinney, R., Puente, J. L. et al. (1999). Enteropathogenic Escherichia coli translocated intimin receptor. Tir, requires a specific chaperone for stable secretion. Mol. Microbiol. 33, 1162-1175. doi: 10.1046/j.1365-2958.1999.01558.x

Akeda, Y., and Galán, J. E. (2005). Chaperone release and unfolding of substrates in type III secretion. Nature 437, 911-915. doi: 10.1038/nature03992

Anderson, D. M., and Schneewind, O. (1997). A mRNA signal for the type III secretion of Yop proteins by Yersinia enterocolitica. Science 278, 1140-1143. doi: 10.1126/science.278.5340.1140

Angus, A. A., Agapakis, C. M., Fong, S., Yerrapragada, S., Estrada-De Los Santos, P., Yang, P., et al. (2014). Plant-associated symbiotic Burkholderia species lack hallmark strategies required in mammalian pathogenesis. PLoS ONE 9:e83779. doi: 10.1371/journal.pone.0083779

Attree, O., and Attree, I. (2001). A second type III secretion system in Burkholderia pseudomallei: who is the real culprit?. Microbiology 147, 3197-3199. doi: 10.1099/00221287-147-12-3197

Barrett, B. S., Picking, W. L., Picking, W. D., and Middaugh, C. R. (2008). The response of type three secretion system needle proteins $\mathrm{MxiH} \Delta 5$, BsaL $\Delta 5$, and $\operatorname{PrgI} \Delta 5$ to temperature and $\mathrm{pH}$. Proteins 73, 632-643. doi: 10.1002/prot.22085

Bast, A., Krause, K., Schmidt, I. H., Pudla, M., Brakopp, S., Hopf, V., et al. (2014). Caspase-1-dependent and -independent cell death pathways in Burkholderia pseudomallei infection of macrophages. PLoS Pathog. 10:e1003986. doi: 10.1371/journal.ppat.1003986

Birtalan, S., and Ghosh, P. (2001). Structure of the Yersinia type III secretory system chaperone SycE. Nat. Struct. Mol. Biol. 8, 974-978. doi: 10.1038/nsb1101-974

Blocker, A., Gounon, P., Larquet, E., Niebuhr, K., Cabiaux, V., Parsot, C., et al. (1999). The tripartite type III secreton of Shigella flexneri inserts IpaB and IpaC into host membranes. J. Cell Biol. 147, 683-693. doi: 10.1083/jcb.147.3.683

Blocker, A., Jouihri, N., Larquet, E., Gounon, P., Ebel, F., Parsot, C., et al. (2001). Structure and composition of the Shigella flexneri 'needle complex', a part of its type III secreton. Mol. Microbiol. 39, 652-663. doi: 10.1046/j.1365-2958.2001.02200.x

Botteaux, A., Sory, M. P., Biskri, L., Parsot, C., and Allaoui, A. (2009). $\mathrm{MxiC}$ is secreted by and controls the substrate specificity of the Shigella flexneri type III secretion apparatus. Mol. Microbiol. 71, 449-460. doi: 10.1111/j.1365-2958.2008.06537.x

Brett, P. J., DeShazer, D., and Woods, D. E. (1998). Note Burkholderia thailandensis sp. nov., a Burkholderia pseudomallei-like species. Int. J. Syst. Bacteriol. 48, 317-320. doi: 10.1099/00207713-48-1-317

Burtnick, M. N., Brett, P. J., Nair, V., Warawa, J. M., Woods, D. E., and Gherardini, F. C. (2008). Burkholderia pseudomallei type III secretion system mutants exhibit delayed vacuolar escape phenotypes in RAW 264.7 murine macrophages. Infect. Immun. 76, 2991-3000. doi: 10.1128/IAI.00263-08

Büttner, D. (2012). Protein export according to schedule: architecture, assembly, and regulation of type III secretion systems from plant-and animal-pathogenic bacteria. Microbiol. Mol. Biol. Rev. 76, 262-310. doi: 10.1128/MMBR.05017-11

Büttner, D., and He, S. Y. (2009). Type III protein secretion in plant pathogenic bacteria. Plant Physiol. 150, 1656-1664. doi: 10.1104/pp.109.139089

Cambronne, E. D., Cheng, L. W., and Schneewind, O. (2000). LcrQ/YscM1, regulators of the Yersinia yop virulon, are injected into host cells by a chaperone-dependent mechanism. Mol. Microbiol. 37, 263-273. doi: 10.1046/j.1365-2958.2000.01974.x

Campbell-Valois, F.-X., Sachse, M., Sansonetti, P. J., and Parsot, C. (2015). Escape of actively secreting Shigella flexneri from ATG8/LC3-positive vacuoles formed during Cell-To-Cell spread is facilitated by IcsB and VirA. MBio 6:e02567-14. doi: $10.1128 / \mathrm{mBio} .02567-14$

Chang, J., Chen, J., and Zhou, D. (2005). Delineation and characterization of the actin nucleation and effector translocation activities of Salmonella SipC. Mol. Microbiol. 55, 1379-1389. doi: 10.1111/j.1365-2958.2004.04480.x

Chen, Y., Schröder, I., French, C. T., Jaroszewicz, A., Yee, X. J., The, B. E., et al. (2014). Characterization and analysis of the Burkholderia pseudomallei BsaN virulence regulon. BMC Microbiol. 14:206. doi: 10.1186/s12866-014-0206-6

Cheng, A. C., and Currie, B. J. (2005). Melioidosis: epidemiology, pathophysiology, and management. Clin. Microbiol. Rev. 18, 383-416. doi: 10.1128/CMR.18.2.383-416.2005
Chirakul, S., Bartpho, T., Wongsurawat, T., Taweechaisupapong, S., Karoonutaisiri, N., Talaat, A. M., et al. (2014). Characterization of BPSS1521 (bprD), a regulator of Burkholderia pseudomallei virulence gene expression in the mouse model. PLoS ONE 9:e104313. doi: 10.1371/journal.pone.0104313

Costa, T. R. D., Felisberto-Rodrigues, C., Meir, A., Prevost, M. S., Redzej, A., Trokter, M., et al. (2015). Secretion systems in Gram-negative bacteria: structural and mechanistic insights. Nat. Rev. Microbiol. 13, 343-359. doi: $10.1038 /$ nrmicro3456

Cui, J., Yao, Q., Li, S., Ding, X., Lu, Q., Mao, H., et al. (2010). Glutamine deamidation and dysfunction of ubiquitin/NEDD8 induced by a bacterial effector family. Science 329, 1215-1218. doi: 10.1126/science.1193844

Cullinane, M., Gong, L., Li, X., Adler, N.-L., Tra, T., Adler, B., et al. (2008). Stimulation of autophagy suppresses the intracellular survival of Burkholderia pseudomallei in mammalian cell lines. Autophagy 4, 744-753. doi: 10.4161/auto.6246

Currie, B. J., Ward, L., and Cheng, A. C. (2010). The epidemiology and clinical spectrum of melioidosis: 540 cases from the 20 year Darwin prospective study. PLoS Negl. Trop. Dis. 4:e900. doi: 10.1371/journal.pntd.0000900

D’Cruze, T., Gong, L., Treerat, P., Ramm, G., Boyce, J. D., Prescott, M., et al. (2011). Role for the Burkholderia pseudomallei type three secretion system cluster $1 \mathrm{bpscN}$ gene in virulence. Infect. Immun. 79, 3659-3664. doi: 10.1128/IAI.01351-10

Darwin, K. H., and Miller, V. L. (2001). Type III secretion chaperone-dependent regulation: activation of virulence genes by SicA and InvF in Salmonella typhimurium. EMBO J. 20, 1850-1862. doi: 10.1093/emboj/20.8.1850

Dean, P. (2011). Functional domains and motifs of bacterial type III effector proteins and their roles in infection. FEMS Microbiol. Rev. 35, 1100-1125. doi: 10.1111/j.1574-6976.2011.00271.x

Deng, W., Li, Y., Hardwidge, P. R., Frey, E. A., Pfuetzner, R. A., Lee, S., et al. (2005). Regulation of type III secretion hierarchy of translocators and effectors in attaching and effacing bacterial pathogens. Infect. Immun. 73, 2135-2146. doi: 10.1128/IAI.73.4.2135-2146.2005

Deng, W., Puente, J. L., Gruenheid, S., Li, Y., Vallance, B. A., Vázquez, A., et al. (2004). Dissecting virulence: systematic and functional analyses of a pathogenicity island. Proc. Natl. Acad. Sci. U.S.A. 101, 3597-3602. doi: 10.1073/pnas.0400326101

Diepold, A., Amstutz, M., Abel, S., Sorg, I., Jenal, U., and Cornelis, G. R. (2010). Deciphering the assembly of the Yersinia type III secretion injectisome. EMBO J. 29, 1928-1940. doi: 10.1038/emboj.2010.84

Diepold, A., and Wagner, S. (2014). Assembly of the bacterial type III secretion machinery. FEMS Microbiol. Rev. 38, 802-822. doi: 10.1111/1574-6976.12061

Diepold, A., Wiesand, U., and Cornelis, G. R. (2011). The assembly of the export apparatus (YscR. S, T, U, V) of the Yersinia type III secretion apparatus occurs independently of other structural components and involves the formation of an YscV oligomerMol. Microbiol. 82, 502-514. doi: 10.1111/j.1365-2958.2011.07830.x

Druar, C., Yu, F., Barnes, J. L., Okinaka, R. T., Chantratita, N., Beg, S., et al. (2008). Evaluating Burkholderia pseudomallei Bip proteins as vaccines and Bip antibodies as detection agents. FEMS Immunol. Med. Microbiol. 52, 78-87. doi: 10.1111/j.1574-695X.2007.00345.x

Du, J., Reeves, A. Z., Klein, J. A., Twedt, D. J., Knodler, L. A., and Lesser, C. F. (2016). The type III secretion system apparatus determines the intracellular niche of bacterial pathogens.. Proc. Natl. Acad. Sci. U.S.A. 113, 4794-4799. doi: 10.1073/pnas.1520699113

Egan, F., Barret, M., and O'Gara, F. (2014). The SPI-1-like Type III secretion system: more roles than you think.. Front. Plant Sci. 5:34. doi: $10.3389 /$ fpls.2014.00034

Ehrbar, K., Friebel, A., Miller, S. I., and Hardt, W.-D. (2003). Role of the Salmonella pathogenicity island 1 (SPI-1) protein InvB in type III secretion of SopE and SopE2, two Salmonella effector proteins encoded outside of SPI-1. J. Bacteriol. 185, 6950-6967. doi: 10.1128/JB.185.23.6950-6967.2003

Ehrbar, K., Hapfelmeier, S., Stecher, B., andHardt, W.-D. (2004). InvB is required for type III-dependent secretion of SopA in Salmonella enterica serovar Typhimurium. J. Bacteriol. 186, 1215-1219. doi: 10.1128/JB.186.4.1215-1219.2004

Ehrbar, K., Winnen, B., and Hardt, W.-D. (2006). The chaperone binding domain of SopE inhibits transport via flagellar and SPI-1 TTSS in the absence of InvB. Mol. Microbiol. 59, 248-264. doi: 10.1111/j.1365-2958.2005.04931.x 
Epler, C. R., Dickenson, N. E., Olive, A. J., Picking, W. L., and Picking, W. D. (2009). Liposomes recruit IpaC to the Shigella flexneri type III secretion apparatus needle as a final step in secretion induction. Infect. Immun. 77, 2754-2761. doi: 10.1128/IAI.00190-09

Erhardt, M., Mertens, M. E., Fabiani, F. D., and Hughes, K. T. (2014). ATPaseindependent type-III protein secretion in Salmonella enterica. PLoS Genet. 10:e1004800. doi: 10.1371/journal.pgen.1004800

Erskine, P. T., Knight, M. J., Ruaux, A., Mikolajek, H., Sang, N. W. F., Withers, J., et al. (2006). High resolution structure of BipD: an invasion protein associated with the type III secretion system of Burkholderia pseudomallei. J. Mol. Biol. 363, 125-136. doi: 10.1016/j.jmb.2006.07.069

Espina, M., Ausar, S. F., Middaugh, C. R., Baxter, M. A., Picking, W. D., and Picking, W. L. (2007). Conformational stability and differential structural analysis of LcrV, PcrV, BipD, and SipD from type III secretion systems. Protein Sci. 16, 704-714. doi: 10.1110/ps.062645007

Espina, M., Olive, A. J., Kenjale, R., Moore, D. S., Ausar, S. F., Kaminski, R. W., et al. (2006). IpaD localizes to the tip of the type III secretion system needle of Shigella flexneri. Infect. Immun. 74, 4391-4400. doi: 10.1128/IAI.00440-06

Forsberg, Å., Viitanen, A.-M., Skurnik, M., and Wolf-Watz, H. (1991). The surface-located YopN protein is involved in calcium signal transduction in Yersinia pseudotuberculosis. Mol. Microbiol. 5, 977-986. doi: 10.1111/j.1365-2958.1991.tb00773.x

French, C. T., Toesca, I. J., Wu, T.-H., Teslaa, T., Beaty, S. M., Wong, W., et al. (2011). Dissection of the Burkholderia intracellular life cycle using a photothermal nanoblade. Proc. Natl. Acad. Sci. U.S.A. 108, 12095-12100. doi: $10.1073 /$ pnas. 1107183108

Frithz-Lindsten, E., Rosqvist, R., Johansson, L., and Forsberg, A. (1995). The chaperone-like protein YerA of Yersinia pseudotuberculosis stabilizes YopE in the cytoplasm but is dispensable for targeting to the secretion loci. Mol. Microbiol. 16, 635-647. doi: 10.1111/j.1365-2958.1995.tb02426.x

Fu, Y., and Galán, J. E. (1998). Identification of a specific chaperone for SptP, a substrate of the centisome 63 type III secretion system of Salmonella typhimurium. J. Bacteriol. 180, 3393-3399.

Galán, J. E. (2009). Common themes in the design and function of bacterial effectors. Cell Host Microbe 5, 571-579. doi: 10.1016/j.chom.2009.04.008

Galán, J. E., and Curtiss, R. (1989). Cloning and molecular characterization of genes whose products allow Salmonella Typhimurium to penetrate tissue culture cells. Proc. Natl. Acad. Sci. U.S.A. 86, 6383-6387. doi: $10.1073 /$ pnas.86.16.6383

Galán,. J. E., Lara-Tejero, M., Marlovits, T. C., and Wagner, S. (2014). Bacterial type III secretion systems: specialized nanomachines for protein delivery into target cells. Annu. Rev. Microbiol. 68:415. doi: 10.1146/annurev-micro-092412-155725

Gemski, P., Lazere, J. R., Casey, T., and Wohlhieter, J. A. (1980). Presence of a virulence-associated plasmid in Yersinia pseudotuberculosis. Infect. Immun. 28, 1044-1047.

Gong, L., Cullinane, M., Treerat, P., Ramm, G., Prescott, M., Adler, B., et al. (2011). The Burkholderia pseudomallei type III secretion system and BopA are required for evasion of LC3-associated phagocytosis. PLOS ONE 6:e17852. doi: 10.1371/journal.pone.0017852

Gong, L., Lai, S.-C., Treerat, P., Prescott, M., Adler, B., Boyce, J. D., et al. (2015). Burkholderia pseudomallei Type III secretion system cluster 3 ATPase BsaS, a chemotherapeutic Target for Small-Molecule ATPase Inhibitors. Infect. Immun. 83, 1276-1285. doi: 10.1128/IAI.03070-14

Gophna, U., Ron, E. Z., and Graur, D. (2003). Bacterial type III secretion systems are ancient and evolved by multiple horizontal-transfer events. Gene 312, 151-163. doi: 10.1016/S0378-1119(03)00612-7

Gutierrez, M. G., Pfeffer, T. L., and Warawa, J. M. (2015a). Type 3 secretion system cluster 3 is a critical virulence determinant for lung-specific melioidosis. PLoS Negl. Trop. Dis. 9:e3441. doi: 10.1371/journal.pntd.0003441

Gutierrez, M. G., Yoder-Himes, D. R., and Warawa, J. M. (2015b). Comprehensive identification of virulence factors required for respiratory melioidosis using Tn-seq mutagenesis. Front. Cell. Infect. Microbiol. 5:78. doi: 10.3389/fcimb.2015.00078

Haque, A., Chu, K., Easton, A., Stevens, M. P., Galyov, E. E., Atkins, T., et al. (2006). A live experimental vaccine against Burkholderia pseudomallei Elicits CD4+ T Cell-Mediated Immunity. Priming T Cells Specific for 2 Type III Secretion System Proteins. J. Infect. Dis. 194, 1241-1248. doi: 10.1086/508217
Haraga, A., West, T. E., Brittnacher, M. J., Skerrett, S. J., and Miller, S. I. (2008). Burkholderia thailandensis as a model system for the study of the virulence-associated type III secretion system of Burkholderia pseudomallei. Infect. Immun. 76, 5402-5411. doi: 10.1128/IAI.00626-08

Hardt, W.-D., Chen, L.-M., Schuebel, K. E., Bustelo, X. R., and Galán, J. E. (1998). S. Typhimurium encodes an activator of Rho GTPases that induces membrane ruffling and nuclear responses in host cells. Cell 93, 815-826. doi: 10.1016/S0092-8674(00)81442-7

Hayward, R. D., Cain, R. J., McGhie, E. J., Phillips, N., Garner, M. J., and Koronakis, V. (2005). Cholesterol binding by the bacterial type III translocon is essential for virulence effector delivery into mammalian cells. Mol. Microbiol. 56, 590-603. doi: 10.1111/j.1365-2958.2005.04568.x

Hayward, R. D., and Koronakis, V. (1999). Direct nucleation and bundling of actin by the SipC protein of invasive Salmonella. EMBO J. 18, 4926-4934. doi: 10.1093/emboj/18.18.4926

Heine, S. J., Diaz-McNair, J., Martinez-Becerra, F. J., Choudhari, S. P., Clements, J. D., Picking, W. L., et al. (2013). Evaluation of immunogenicity and protective efficacy of orally delivered Shigella type III secretion system proteins IpaB and IpaD. Vaccine 31, 2919-2929. doi: 10.1016/j.vaccine.2013. 04.045

Hemrajani, C., Berger, C. N., Robinson, K. S., Marchès, O., Mousnier, A., and Frankel, G. (2010). NleH effectors interact with Bax inhibitor-1 to block apoptosis during enteropathogenic Escherichia coli infection. Proc. Natl. Acad. Sci. U.S.A. 107, 3129-3134. doi: 10.1073/pnas.0911609106

Holden, M. T. G., Titball, R. W., Peacock, S. J., Cerdeño-Tárraga, A. M., Atkins, T., Crossman, L. C., et al. (2004). Genomic plasticity of the causative agent of melioidosis. Burkholderia pseudomallei. Proc. Natil. Acad. Sci. U.S.A. 101, 14240-14245. doi: 10.1073/pnas.0403302101

Hovis, K. M., Mojica, S., McDermott, J. E., Pedersen, L., Simhi, C., Rank, R. G., et al. (2013). Genus-optimized strategy for the identification of Chlamydial type III secretion substrates. Pathog. Dis. 69, 213-222. doi: 10.1111/2049-632X. 12070

Hu, B., Lara-Tejero, M., Kong, Q., Galán, J. E., and Liu, J. (2017). In situ molecular architecture of the salmonella Type III secretion machine. Cell 168, 1065-1074. doi: 10.1016/j.cell.2017.02.022

Iriarte, M., Sory, M.-P., Boland, A., Boyd, A. P., Mills, S. D., Cornelis, G. R. et al. (1998). TyeA, a protein involved in control of Yop release and in translocation of Yersinia Yop effectors. EMBO J. 17, 1907-1918. doi: 10.1093/emboj/17.7.1907

Jarvis, K. G., Giron, J. A., Jerse, A. E., McDaniel, T. K., Donnenberg, M. S., and Kaper, J. B. (1995). Enteropathogenic Escherichia coli contains a putative type III secretion system necessary for the export of proteins involved in attaching and effacing lesion formation. Proc. Natl. Acad. Sci. U.S.A. 92, 7996-8000. doi: 10.1073/pnas.92.17.7996

Jitprasutwit, S., Thaewpia, W., Muangsombut, V., Lulitanond, A., Leelayuwat, C., Lertmemongkolchai, G., et al. (2010). Effect of acidic pH on the invasion efficiency and the type III secretion system of Burkholderia thailandensis. J. Microbiol. 48, 526-532. doi: 10.1007/s12275-010-0078-x

Johnson, S., Roversi, P., Espina, M., Olive, A., Deane, J. E., Birket, S., et al. (2007). Self-chaperoning of the type III secretion system needle tip proteins IpaD and BipD. J. Biol. Chem. 282, 4035-4044. doi: 10.1074/jbc.M6079 45200

Jones, A. L., Beveridge, T. J., and Woods, D. E. (1996). Intracellular survival of Burkholderia pseudomallei. Infect. Immun. 64, 782-790.

Kang, W. T., Vellasamy, K. M., Chua, E.-G., and Vadivelu, J. (2015). Functional characterizations of effector protein BipC, a type III secretion system protein, in Burkholderia pseudomallei pathogenesis. J. Infect. Dis. 211, 827-834. doi: 10.1093/infdis/jiu492

Kang, W. T., Vellasamy, K. M., Rajamani, L., Beuerman, R. W., and Vadivelu, J. (2016a). Burkholderia pseudomallei type III secreted protein BipC: role in actin modulation and translocation activities required for the bacterial intracellular lifecycle. Peer J. 4:e2532. doi: 10.7717/peerj.2532

Kang, W. T., Vellasamy, K. M., and Vadivelu, J. (2016b). Eukaryotic pathways targeted by the type III secretion system effector protein. BipC, involved in the intracellular lifecycle of Burkholderia pseudomallei. Sci. Rep. 6:33528. doi: 10.1038/srep33528

Kayath, C. A., Hussey, S., Nagra, K., Philpott, D., and Allaoui, A. (2010). Escape of intracellular Shigella from autophagy requires binding to 
cholesterol through the type III effector, IcsB. Microbes Infect. 12, 956-966. doi: 10.1016/j.micinf.2010.06.006

Kim, J. S., Eom, J. S., Im Jang, J., Kim, H. G., Seo, D. W. Bang, I. S., et al (2011). Role of Salmonella pathogenicity island 1 protein IacP in Salmonella enterica serovar Typhimurium pathogenesis. Infect. Immun. 79, 1440-1450. doi: 10.1128/IAI.01231-10

Klein, J. A., Dave, B. M., Raphenya, A. R., McArthur, A. G., and Knodler, L. A. (2017). Functional relatedness in the Inv/Mxi-Spa type III secretion system family. Mol. Microbiol. 103, 973-991. doi: 10.1111/mmi.13602

Knight, M. J., Ruaux, A., Mikolajek, H., Erskine, P. T., Gill, R., Wood, S. P., et al. (2006). Crystallization and preliminary X-ray diffraction analysis of BipD, a virulence factor from Burkholderia pseudomallei. Acta Crystallogr. Sect. F Struct. Biol. Cryst. Commun. 62, 761-764. doi: 10.1107/S1744309106024857

Kresse, A. U., Beltrametti, F., Müller, A., Ebel, F., and Guzmán, C. A. (2000). Characterization of SepL of enterohemorrhagic Escherichia coli. J. Bacteriol. 182, 6490-6498. doi: 10.1128/JB.182.22.6490-6498.2000

Kubori, T., and Galán, J. E. (2002). Salmonella type III secretion-associated protein InvE controls translocation of effector proteins into host cells. J. Bacteriol. 184, 4699-4708. doi: 10.1128/JB.184.17.4699-4708.2002

Kubori, T., Matsushima, Y., Nakamura, D., Uralil, J., Lara-Tejero, M., Sukhan, A., et al. (1998). Supramolecular structure of the Salmonella Typhimurium type III protein secretion system. Science 280, 602-605. doi: $10.1126 /$ science. 280.5363 .602

Kubori, T., Sukhan, A., Aizawa, S.-I., and Galán, J. E. (2000). Molecular characterization and assembly of the needle complex of the Salmonella Typhimurium type III protein secretion system. Proc. Natl. Acad. Sci. U.S.A. 97, 10225-10230. doi: 10.1073/pnas. 170128997

Lafont, F., Tran Van Nhieu, G., Hanada, K., Sansonetti, P., and van der Goot, G. F. (2002). Initial steps of Shigella infection depend on the cholesterol/sphingolipid raft-mediated CD44-IpaB interaction. EMBO J. 21, 4449-4457. doi: 10.1093/emboj/cdf457

Lee, S. H., and Galán, J. E. (2003). InvB is a type III secretion-associated chaperone for the Salmonella enterica effector protein SopE. J. Bacteriol. 185, 7279-7284. doi: 10.1128/JB.185.24.7279-7284.2003

Lee, S. H., and Galán, J. E. (2004). Salmonella type III secretion-associated chaperones confer secretion-pathway specificity. Mol. Microbiol. 51, 483-495. doi: 10.1046/j.1365-2958.2003.03840.x

Lee, Y. H., Chen, Y., Ouyang, X., and Gan, Y.-H. (2010). Identification of tomato plant as a novel host model for Burkholderia pseudomallei. BMC Microbiol. 10:28. doi: 10.1186/1471-2180-10-28

Limmathurotsakul, D., Golding, N., Dance, D. A., Messina, J. P., Pigott, D. M., Moyes, C. L., et al. (2016). Predicted global distribution of Burkholderia pseudomallei and burden of melioidosis. Nat. Microbiol. 1:15008. doi: 10.1038/nmicrobiol.2015.8

Lipscomb, L., and Schell, M. A. (2011). Elucidation of the regulon and cis-acting regulatory element of $\mathrm{HrpB}$, the AraC-type regulator of a plant pathogenlike type III secretion system in Burkholderia pseudomallei. J. Bacteriol. 193, 1991-2001. doi: 10.1128/jb.01379-10

Madan, R., Rastogi, R., Parashuraman, S., and Mukhopadhyay, A. (2012). Salmonella acquires lysosome-associated membrane protein 1 (LAMP1) on phagosomes from Golgi via SipC protein-mediated recruitment of host Syntaxin6. J. Biol. Chem. 287, 5574-5587. doi: 10.1074/jbc.M111. 286120

Markham, A. P., Birket, S. E., Picking, W. D., Picking, W. L., and Middaugh, C. R. (2008). pH sensitivity of type III secretion system tip proteins. Proteins 71, 1830-1842. doi: 10.1002/prot.21864

Marlovits, T. C., Kubori, T., Sukhan, A., Thomas, D. R., Galán, J. E., and Unger, V. M. (2004). Structural insights into the assembly of the type III secretion needle complex. Science 306, 1040-1042. doi: 10.1126/science.1102610

Martinez-Becerra, F. J., Chen, X., Dickenson, N. E., Choudhari, S. P., Harrison, K., Clements, J. D., et al. (2013). Characterization of a novel fusion protein from $\mathrm{IpaB}$ and IpaD of Shigella sand its potential as a pan-Shigella vaccine. Infect. Immun. 81, 4470-4477. doi: 10.1128/IAI.00859-13

Martinez-Becerra, F. J., Kissmann, J. M., Diaz-McNair, J., Choudhari, S. P., Quick, A. M., Mellado-Sanchez, G., et al. (2012). Broadly protective Shigella vaccine based on type III secretion apparatus proteins. Infect. Immun. 80, 1222-1231. doi: 10.1128/IAI.06174-11
Maurelli, A. T., Baudry, B. H., d'Hauteville, H., Hale, T. L., and Sansonetti, P. J. (1985). Cloning of plasmid DNA sequences involved in invasion of HeLa cells by Shigella flexneri. Infect. Immun. 49, 164-171.

McGhie, E. J., Hayward, R. D., and Koronakis, V. (2001). Cooperation between actin-binding proteins of invasive Salmonella: SipA potentiates SipC nucleation and bundling of actin. EMBO J. 20, 2131-2139. doi: 10.1093/emboj/20. 9.2131

Miao, E. A., Mao, D. P., Yudkovsky, N., Bonneau, R., Lorang, C. G., Warren, S. E., et al. (2010). Innate immune detection of the type III secretion apparatus through the NLRC4 inflammasome. Proc. Natl. Acad. Sci. U.S.A. 107, 3076-3080. doi: 10.1073/pnas.0913087107

Michiels, T., and Cornelis, G. R. (1991). Secretion of hybrid proteins by the Yersinia Yop export system. J. Bacteriol. 173, 1677-1685. doi: 10.1128/jb.173.5.1677-1685.1991

Moore, R. A., Reckseidler-Zenteno, S., Kim, H., Nierman, W., Yu, Y., Tuanyok, A., et al. (2004). Contribution of gene loss to the pathogenic evolution of Burkholderia pseudomallei and Burkholderia mallei. Infect. Immun. 72, 4172-4187. doi: 10.1128/IAI.72.7.4172-4187.2004

Muangman, S., Korbsrisate, S., Muangsombut, V., Srinon, V., Adler, N. L., Schroeder, G. N., et al. (2011). BopC is a type III secreted effector protein of Burkholderia pseudomallei. FEMS Microbiol. Lett. 323, 75-82. doi: 10.1111/j.1574-6968.2011.02359.x

Muangsombut, V., Suparak, S., Pumirat, P., Damnin, S., Vattanaviboon, P., Thongboonkerd, V., et al. (2008). Inactivation of Burkholderia pseudomallei bsaQ results in decreased invasion efficiency and delayed escape of bacteria from endocytic vesicles. Arch. Microbiol. 190, 623-631. doi: $10.1007 /$ s00203-008-0413-3

Myeni, S. K., Wang, L., and Zhou, D. (2013). SipB-SipC complex is essential for translocon formation. PLoS ONE 8:e60499. doi: 10.1371/journal.pone.0060499

Myeni, S. K., and Zhou, D. (2010). The C terminus of SipC binds and bundles F-actin to promote Salmonella invasion. J. Biol. Chem. 285, 13357-13363. doi: 10.1074/jbc.M109.094045

Ng, M. Y., Wang, M., Casey, P. J., Gan, Y.-H., and Hagen, T. (2017). Activation of MAPK/ERK signaling by Burkholderia pseudomallei cycle inhibiting factor (Cif). PLoS ONE 12:e0171464. doi: 10.1371/journal.pone.0171464

Ngauy, V., Lemeshev, Y., Sadkowski, L., and Crawford, G. (2005). Cutaneous melioidosis in a man who was taken as a prisoner of war by the Japanese during World War II. J. Clin. Microbiol. 43, 970-972. doi: 10.1128/JCM.43.2.970-972.2005

Nougayrède, J.-P., Boury, M., Tasca, C., Marchès, O., Milon, A., Oswald, E., et al. (2001). Type III secretion-dependent cell cycle block caused in HeLa cells by enteropathogenic Escherichia coli O103. Infect. Immun. 69, 6785-6795. doi: 10.1128/IAI.69.11.6785-6795.2001

Olive, A. J., Kenjale, R., Espina, M., Moore, D. S., Picking, W. L., and Picking, W. D. (2007). Bile salts stimulate recruitment of IpaB to the Shigella flexneri surface, where it colocalizes with IpaD at the tip of the type III secretion needle. Infect. Immun. 75, 2626-2629. doi: 10.1128/IAI.01599-06

Osiecki, J. C., Barker, J., Picking, W. L., Serfis, A. B., Berring, E., Shah, S., et al. (2001). IpaC from Shigella and SipC from Salmonella possess similar biochemical properties but are functionally distinct. Mol. Microbiol. 42, 469-481. doi: 10.1046/j.1365-2958.2001.02654.x

Pal, M., Erskine, P. T., Gill, R. S., Wood, S. P., and Cooper, J. B. (2010). Nearatomic resolution analysis of BipD, a component of the type III secretion system of Burkholderia pseudomallei. Acta Crystallogr. Sect. F Struct. Biol. Cryst. Commun. 66, 990-993. doi: 10.1107/S1744309110026333

Pallett, M. A., Berger, C. N., Pearson, J. S., Hartland, E. L., and Frankel, G. (2014). The type III secretion effector NleF of enteropathogenic Escherichia coli activates NF- $\kappa$ B early during infection. Infect. Immun. 82, 4878-4888. doi: 10.1128/IAI.02131-14

Panina, E. M., Mattoo, S., Griffith, N., Kozak, N. A., Yuk, M. H., and Miller, J. F. (2005). A genome-wide screen identifies a Bordetella type III secretion effector and candidate effectors in other species. Mol. Microbiol. 58, 267-279. doi: 10.1111/j.1365-2958.2005.04823.x

Parsot, C., Ménard, R., Gounon, P., and Sansonetti, P. J. (1995). Enhanced secretion through the Shigella flexneri Mxi-Spa translocon leads to assembly of extracellular proteins into macromolecular structures. Mol. Microbiol. 16, 291-300. doi: 10.1111/j.1365-2958.1995.tb02301.x 
Paul, K., Erhardt, M., Hirano, T., Blair, D. F., and Hughes, K. T. (2008). Energy source of flagellar type III secretion. Nature 451, 489-492. doi: 10.1038/nature06497

Pearson, T., Giffard, P., Beckstrom-Sternberg, S., Auerbach, R., Hornstra, H., Tuanyok, A., et al. (2009). Phylogeographic reconstruction of a bacterial species with high levels of lateral gene transfer. BMC Biol. 7:78. doi: $10.1186 / 1741-7007-7-78$

Pei, J., and Grishin, N. V. (2009). The Rho GTPase inactivation domain in Vibrio cholerae MARTX toxin has a circularly permuted papain-like thiol protease fold. Proteins 77, 413-419. doi: 10.1002/prot.22447

Persson, C., Carballeira, N., Wolf-Watz, H., and Fällman, M. (1997). The PTPase YopH inhibits uptake of Yersinia, tyrosine phosphorylation of p130Cas and FAK, and the associated accumulation of these proteins in peripheral focal adhesions. EMBO J. 16, 2307-2318. doi: 10.1093/emboj/16.9.2307

Picking, W. L., Nishioka, H., Hearn, P. D., Baxter, M. A., Harrington, A. T., Blocker, A., et al. (2005). IpaD of Shigella flexneri is independently required for regulation of Ipa protein secretion and efficient insertion of IpaB and IpaC into host membranes. Infect. Immun. 73, 1432-1440. doi: 10.1128/IAI.73.3.1432-1440.2005

Pilatz, S., Breitbach, K., Hein, N., Fehlhaber, B., Schulze, J., Brenneke, B., et al. (2006). Identification of Burkholderia pseudomallei genes required for the intracellular life cycle and in vivo virulence. Infect. Immun. 74, 3576-3586. doi: 10.1128/IAI.01262-05

Pruksachartvuthi, S., Aswapokee, N., and Thankerngpol, K. (1990). Survival of Pseudomonas pseudomallei in human phagocytes. J. Med. Microbiol. 31, 109-114. doi: 10.1099/00222615-31-2-109

Pumirat, P., Vander Broek, C., Juntawieng, N., Muangsombut, V., Kiratisin, P., Pattanapanyasat, K., et al. (2014). Analysis of the prevalence, secretion and function of a cell cycle-inhibiting factor in the melioidosis pathogen Burkholderia pseudomallei. PLoS ONE 9:e96298. doi: 10.1371/journal.pone.0096298

Radics, J., Königsmaier, L., and Marlovits, T. C. (2014). Structure of a pathogenic type 3 secretion system in action. Nat. Struct. Mol. Biol. 21, 82-87. doi: $10.1038 / \mathrm{nsmb} .2722$

Rainbow, L., Hart, C. A., and Winstanley, C. (2002). Distribution of type III secretion gene clusters in Burkholderia pseudomallei. B. thailandensis and B. mallei. J. Med. Microbiol. 51, 374-384. doi: 10.1099/0022-1317-51-5-374

Roehrich, A. D., Bordignon, E., Mode, S., Shen, D.-K., Liu, X., Blocker, A. J. et al. (2016). Steps for Shigella Gatekeeper MxiC Function in Hierarchical Type III Secretion Regulation. J. Biol. Chem. 292, 1705-1723. doi: 10.1074/jbc.M116.746826

Roehrich, A. D., Guillossou, E., Blocker, A. J., and Martinez-Argudo, I. (2013). Shigella IpaD has a dual role: signal transduction from the type III secretion system needle tip and intracellular secretion regulation. Mol. Microbiol. 87, 690-706. doi: $10.1111 / \mathrm{mmi} .12124$

Rossier, O., Wengelnik, K., Hahn, K., and Bonas, U. (1999). The Xanthomonas Hrp type III system secretes proteins from plant and mammalian bacterial pathogens. Proc. Natl. Acad. Sci. U.S.A. 96, 9368-9373. doi: $10.1073 /$ pnas. 96.16 .9368

Rotz, L. D., Khan, A. S., Lillibridge, S. R., Ostroff, S. M., and Hughes, J. M. (2002). Public health assessment of potential biological terrorism agents. Emerg. Infect. Dis. 8, 225-230. doi: 10.3201/eid0802.010164

Roversi, P., Johnson, S., Field, T., Deane, J. E., Galyov, E. E., and Lea, S. M. (2006). Expression, purification, crystallization and preliminary crystallographic analysis of BipD, a component of the Burkholderia pseudomallei type III secretion system. Acta Crystallogr. Sect. F Struct. Biol. Cryst. Commun. 62, 861-864. doi: 10.1107/S1744309106027035

Sato, H., Frank, D. W., Hillard, C. J., Feix, J. B., Pankhaniya, R. R., Moriyama, K., et al. (2003). The mechanism of action of the Pseudomonas aeruginosaencoded type III cytotoxin, ExoU. EMBO J. 22, 2959-2969. doi: 10.1093/emboj/ cdg290

Schesser, K., Frithz-Lindsten, E., and Wolf-Watz, H. (1996). Delineation and mutational analysis of the Yersinia pseudotuberculosis YopE domains which mediate translocation across bacterial and eukaryotic cellular membranes. J. Bacteriol. 178, 7227-7233. doi: 10.1128/jb.178.24.7227-7233.1996

Schraidt, O., and Marlovits, T. C. (2011). Three-dimensional model of Salmonella's needle complex at subnanometer resolution. Science 331, 1192-1195. doi: 10.1126/science. 1199358
Sim, S. H., Yu, Y., Lin, C. H., Karuturi, R. K., Wuthiekanun, V., Tuanyok, A., et al. (2008). The core and accessory genomes of Burkholderia pseudomallei: implications for human melioidosis. PLoS Pathog. 4:e1000178. doi: 10.1371/journal.ppat.1000178

Smith, M. D., Angus, B. J., Wuthiekanun, V., and White, N. J. (1997). Arabinose assimilation defines a nonvirulent biotype of Burkholderia pseudomallei. Infect. Immun. 65, 4319-4321.

Sory, M.-P., Boland, A., Lambermont, I., and Cornelis, G. R. (1995). Identification of the YopE and YopH domains required for secretion and internalization into the cytosol of macrophages, using the cyaA gene fusion approach. Proc. Natl. Acad. Sci. U.S.A. 92, 11998-12002.

Srinivasan, A., Kraus, C. N., DeShazer, D., Becker, P. M., Dick, J. D., Spacek, L., et al. (2001). Glanders in a military research microbiologist. N. Engl. J. Med. 345, 256-258. doi: 10.1056/NEJM200107263450404

Srinon, V., Muangman, S., Imyaem, N., Muangsombut, V. L. A., Adler, N. R., Galyov, E. E., et al. (2013). Comparative assessment of the intracellular survival of the Burkholderia pseudomallei bopC mutant. J. Microbiol. 51, 522-526. doi: 10.1007/s12275-013-2557-3

Stebbins, C. E., and Galán, J. E. (2001). Maintenance of an unfolded polypeptide by a cognate chaperone in bacterial type III secretion. Nature 414, 77-81. doi: $10.1038 / 35102073$

Stensrud, K. F., Adam, P. R., La Mar, C. D., Olive, A. J., Lushington, G. H., Sudharsan, R., et al. (2008). Deoxycholate interacts with IpaD of Shigella flexneri in inducing the recruitment of IpaB to the type III secretion apparatus needle tip. J. Biol. Chem. 283, 18646-18654. doi: 10.1074/jbc.M802799200

Stevens, M. P., Friebel, A., Taylor, L. A., Wood, M. W., Brown, P. J., Galyov, E. E. et al. (2003). A Burkholderia pseudomallei type III secreted protein. BopE, facilitates bacterial invasion of epithelial cells and exhibits guanine nucleotide exchange factor activity. J. Bacteriol. 185, 4992-4996. doi: 10.1128/JB.185.16.4992-4996.2003

Stevens, M. P., Haque, A., Atkins, T., Hill, J., Wood, M. W., Easton, A., et al. (2004). Attenuated virulence and protective efficacy of a Burkholderia pseudomalle $i$ bsa type III secretion mutant in murine models of melioidosis. Microbiology 150, 2669-2676. doi: 10.1099/mic.0.27146-0

Stevens, M. P., Wood, M. W., Taylor, L. A., Monaghan, P., Hawes, P., Jones, P. W., et al. (2002). An Inv/Mxi-Spa-like type III protein secretion system in Burkholderia pseudomallei modulates intracellular behaviour of the pathogen. Mol. Microbiol. 46, 649-659. doi: 10.1046/j.1365-2958.2002.03190.x

Sun, G. W., Chen, Y., Liu, Y., Tan, G.-Y., Ong, C., Gan, H., et al. (2010). Identification of a regulatory cascade controlling Type III Secretion System 3 gene expression in Burkholderia pseudomallei. Mol. Microbiol. 76, 677-689. doi: 10.1111/j.1365-2958.2010.07124.x

Sun, G. W., Lu, J., Pervaiz, S., Cao, W. P., and Gan, Y.-H. (2005). Caspase1 dependent macrophage death induced by Burkholderia pseudomallei. Cell. Microbiol. 7, 1447-1458. doi: 10.1111/j.1462-5822.2005.00569.x

Suparak, S., Kespichayawattana, W., Haque, A., Easton, A., Damnin, S., Lertmemongkolchai, G., et al. (2005). Multinucleated giant cell formation and apoptosis in infected host cells is mediated by Burkholderia pseudomallei type III secretion protein BipB. J. Bacteriol. 187, 6556-6560. doi: 10.1128/JB.187.18.6556-6560.2005

Teh, B. E., French, C. T., Chen, Y., Chen, I. G. J., Wu, T.-H., Gan, H., et al. (2014). Type three secretion system-mediated escape of Burkholderia pseudomallei into the host cytosol is critical for the activation of NF $\kappa$ B. BMC Microbiol. 14:115. doi: 10.1186/1471-2180-14-115

Tippayawat, P., Pinsiri, M., Rinchai, D., Riyapa, D., Romphruk, A., Gan, Y. H., et al. (2011). Burkholderia pseudomallei proteins presented by monocyte-derived dendritic cells stimulate human memory T cells in vitro. Infect. Immun. 79, 305-313. doi: 10.1128/IAI.00803-10

Tippayawat, P., Saenwongsa, W., Mahawantung, J., Suwannasaen, D., Chetchotisakd, P., Limmathurotsakul, D., et al. (2009). Phenotypic and functional characterization of human memory T cell responses to Burkholderia pseudomallei. PLoS Negl. Trop. Dis. 3:e407. doi: 10.1371/journal.pntd.0000407

Treerat, P., Alwis, P., D'Cruze, T., Cullinane, M., Vadivelu, J., Devenish, R. J., et al. (2015). The Burkholderia pseudomallei Proteins BapA and BapC Are Secreted TTSS3 Effectors and BapB levels modulate expression of Bop. PLoS ONE 10:e0143916. doi: 10.1371/journal.pone.0143916

Tuanyok, A., Leadem, B. R., Auerbach, R. K., Beckstrom-Sternberg, S. M., Beckstrom-Sternberg, J. S., Mayo, M., et al. (2008). Genomic islands 
from five strains of Burkholderia pseudomallei. BMC Genomics 9:566. doi: 10.1186/1471-2164-9-566

Tucker, S. C., and Galán, J. E. (2000). omplex function for SicA, a Salmonella enterica serovar typhimurium type III secretion-associated chaperone. J. Bacteriol. 182, 2262-2268. doi: 10.1128/JB.182.8.2262-2268.2000

Upadhyay, A., Wu, H., Williams, C., Field, T., Galyov, E. J., et al. (2008). The guanine-nucleotide-exchange factor BopE from Burkholderia pseudomallei adopts a compact version of the Salmonella SopE/SopE2 fold and undergoes a closed-to-open conformational change upon interaction with Cdc42. Biochem. J. 411, 485-493. doi: 10.1042/BJ20071546

Vander Broek, C. W., Chalmers, K. J., Stevens, M. P., and Stevens, J. M. (2015). Quantitative Proteomic analysis of Burkholderia pseudomallei Bsa Type III secretion system effectors using hypersecreting mutants. Mol. Cell. Proteomics 14, 905-916. doi: 10.1074/mcp.M114.044875

Van Zandt, K. E., Greer, M. T., and Gelhaus, H. C. (2013). Glanders: an overview of infection in humans. Orphanet J. Rare Dis. 8, 131. doi: 10.1186/1750-1172-8-131

Wagner, S., Königsmaier, L., Lara-Tejero, M., Lefebre, M., Marlovits, T. C., and Galán, J. E. (2010). Organization and coordinated assembly of the type III secretion export apparatus. Proc. Natl. Acad. Sci. U.S.A. 107, 17745-17750. doi: 10.1073/pnas.1008053107

Wang, Y., Ouellette, A. N., Egan, C. W., Rathinavelan, T., Im, W., and Da Guzman, R. N. (2007). Differences in the electrostatic surfaces of the type III secretion needle proteins PrgI, BsaL, and MxiH. J. Mol. Biol. 371, 1304-1314. doi: 10.1016/j.jmb.2007.06.034

Warawa, J., and Woods, D. E. (2005). Type III secretion system cluster 3 is required for maximal virulence of Burkholderia pseudomallei in a hamster infection model. FEMS Microbiol. Lett. 242, 101-108. doi: 10.1016/j.femsle.2004.10.045

Warren, S. M., and Young, G. M. (2005). An amino-terminal secretion signal is required for YplA export by the Ysa, Ysc, and flagellar type III secretion systems of Yersinia enterocolitica biovar 1B. J. Bacteriol. 187, 6075-6083. doi: 10.1128/JB.187.17.6075-6083.2005

West, T. E., Myers, N. D., Chantratita, N., Chierakul, W., Limmathurotsakul, D., Wuthiekanun, V., et al. (2014). NLRC4 and TLR5 each contribute to host defense in respiratory melioidosis. PLoS Negl. Trop. Dis. 8:e3178. doi: 10.1371/journal.pntd.0003178

Whitlock, G. C., Deeraksa, A., Qazi, O., Judy, B. M., Taylor, K., Propst, K. L., et al. (2010). Protective response to subunit vaccination against intranasal Burkholderia mallei and B. pseudomallei challenge. Procedia Vaccinol. 2, 73-77. doi: 10.1016/j.provac.2010.03.013

Whitlock,. G. C., Estes, D. M., Young, G. M., Young, B., and Torres, A. G. (2008). Construction of a reporter system to study Burkholderia mallei type III secretion and identification of the BopA effector protein function in intracellular survival. Trans. R. Soc. Trop. Med. Hyg. 102, S127-S133. doi: 10.1016/S0035-9203(08)70029-4

Whitlock, G. C., Valbuena, G. A., Popov, V. L., Judy, B. M., Estes, D. M., and Torres, A. G. (2009). Burkholderia mallei cellular interactions in a respiratory cell model. J. Med. Microbiol. 58, 554-562. doi: 10.1099/jmm.0.007724-0

Whitmore, A. (1913). An account of a glanders-like disease occurring in Rangoon. J. Hyg. 13, 1-34. doi: 10.1017/S0022172400005234

Wilharm, G., Lehmann, V., Krauss, K., Lehnert, B., Richter, S., Ruckdeschel, K., et al. (2004). Yersinia enterocolitica type III secretion depends on the proton motive force but not on the flagellar motor components MotA and MotB. Infect. Immun. 72, 4004-4009. doi: 10.1128/IAI.72.7.4004-4009.2004
Williamson, E. D. (2009). Plague. Vaccine 27, D56-D60. doi: 10.1016/j.vaccine.2009.07.068

Winstanley, C., Hales, B. A., and Hart, C. A. (1999). Evidence for the presence in Burkholderia pseudomallei of a type III secretion system-associated gene cluster. J. Med. Microbiol. 48, 649-656. doi: 10.1099/00222615-48-7-649

Yabuuchi, E., Kosako, Y., Oyaizu, H., Yano, I., Hotta, H., Hashimoto, Y., et al. (1992). Proposal of Burkholderia gen. nov. and transfer of seven species of the genus Pseudomonas homology group II to the new genus, with the type species Burkholderia cepacia (Palleroni and Holmes 1981) comb. nov. Microbiol. Immunol. 36, 1251-1275. doi: 10.1111/j.1348-0421.1992. tb02129.x

Yang, J., Zhao, Y., Shi, J., and Shao, F. (2013). Human NAIP and mouse NAIP1 recognize bacterial type III secretion needle protein for inflammasome activation. Proc. Natl. Acad. Sci. U.S.A. 110, 14408-14413. doi: 10.1073/pnas.1306376110

Young, B. M., and Young, G. M. (2002). YplA is exported by the Ysc, Ysa, and flagellar type III secretion systems of Yersinia enterocolitica. J. Bacteriol. 184, 1324-1334. doi: 10.1128/JB.184.5.1324-1334.2002

Young, G. M., Schmiel, D. H., and Miller, V. L. (1999). A new pathway for the secretion of virulence factors by bacteria: the flagellar export apparatus functions as a protein-secretion system. Proc. Natl. Acad. Sci. U.S.A. 96, 6456-6461. doi: 10.1073/pnas.96.11.6456

Yu, Y., Kim, H. S., Chua, H. H., Lin, C. H., Sim, S. H., Lin, D., et al. (2006). Genomic patterns of pathogen evolution revealed by comparison of Burkholderia pseudomallei, the causative agent of melioidosis, to avirulent Burkholderia thailandensis. BMC Microbiol. 6:46. doi: 10.1186/1471-2180-6-46

Zahrl, D., Wagner, M., Bischof, K., Bayer, M., Zavecz, B., Beranek, A., et al. (2005). Peptidoglycan degradation by specialized lytic transglycosylases associated with type III and type IV secretion systems. Microbiology 151, 3455-3467. doi: 10.1099/mic.0.28141-0

Zarivach, R., Deng, W., Vuckovic, M., Felise, H. B., Nguyen, H. V., Miller, S. I., et al. (2008). Structural analysis of the essential self-cleaving type III secretion proteins EscU and SpaS. Nature 453, 124-127. doi: 10.1038/nature06832

Zhang, L., Wang, Y., Picking, W. L., Picking, W. D., and Da Guzman, R. N. (2006). Solution structure of monomeric BsaL, the type III secretion needle protein of Burkholderia pseudomallei. J. Mol. Biol. 359, 322-330. doi: 10.1016/j.jmb.2006.03.028

Zhao, Y., Yang, J., Shi, J., Gong, Y.-N., Lu, Q., Xu, H., et al. (2011). The NLRC4 inflammasome receptors for bacterial flagellin and type III secretion apparatus. Nature 477, 596-600. doi: 10.1038/nature10510

Zhou, Y., Dong, N., Hu, L., and Shao, F. (2013). The Shigella type three secretion system effector OspG directly and specifically binds to host ubiquitin for activation. PLoS ONE 8:e57558. doi: 10.1371/journal.pone.0057558

Conflict of Interest Statement: The authors declare that the research was conducted in the absence of any commercial or financial relationships that could be construed as a potential conflict of interest.

Copyright (๑) 2017 Vander Broek and Stevens. This is an open-access article distributed under the terms of the Creative Commons Attribution License (CC BY). The use, distribution or reproduction in other forums is permitted, provided the original author(s) or licensor are credited and that the original publication in this journal is cited, in accordance with accepted academic practice. No use, distribution or reproduction is permitted which does not comply with these terms. 